\title{
Thermal Expansion of Long Slender Rods with Forced Convection Cooling Along the Rod Length
}

F.F. Rudder, Jr.

U.S. DEPARTMENT OF COMMERCE Technology Administration National Institute of Standards and Technology

Precision Engineering Division Manufacturing Engineering Laboratory Gaithersburg, MD 20899-0001

QC 



\section{Thermal Expansion of \\ Long Slender Rods with \\ Forced Convection Cooling \\ Along the Rod Length}

F.F. Rudder, Jr.

U.S. DEPARTMENT OF COMMERCE Technology Administration

National Institute of Standards and Technology

Precision Engineering Division

Manufacturing Engineering Laboratory

Gaithersburg, MD 20899-0001

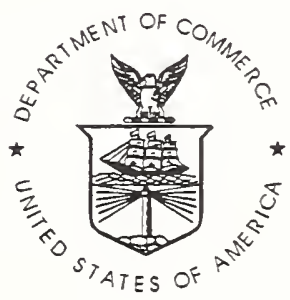

U.S. DEPARTMENT OF COMMERCE William M. Daley, Secretary

TECHNOLOGY ADMINISTRATION

Mary L. Good, Under Secretary for Technology

NATIONAL INSTITUTE OF STANDARDS

AND TECHNOLOGY

Arati Prabhakar, Director 

CONTENTS

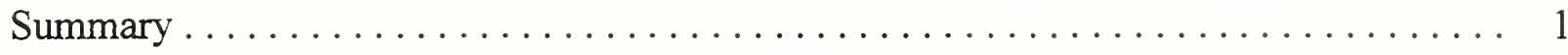

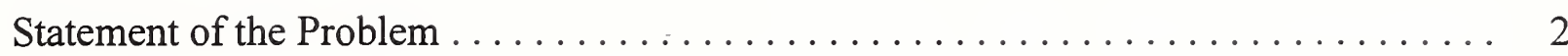

The NIST Octahedral Hexapod $\ldots \ldots \ldots \ldots \ldots \ldots \ldots \ldots \ldots \ldots \ldots \ldots \ldots \ldots \ldots \ldots$

Heat Conduction / Transfer Model $\ldots \ldots \ldots \ldots \ldots \ldots \ldots \ldots \ldots \ldots \ldots \ldots$

Example Calculations ................................. 9

Parameters for Example Calculations . . . . . . . . . . . . . . . . 10

Step Response for Constant Temperature Input $\ldots \ldots \ldots \ldots \ldots \ldots \ldots \ldots \ldots \ldots$

Step Response for Constant Heat Flux Input $\ldots \ldots \ldots \ldots \ldots \ldots \ldots \ldots \ldots \ldots \ldots$

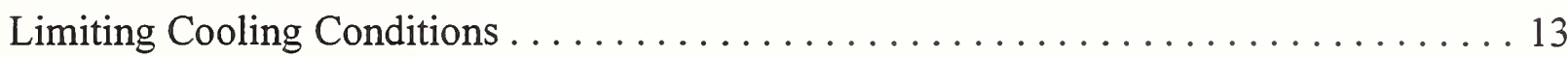

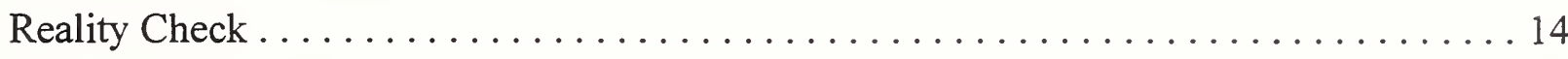

Metrology Considerations ................................. 15

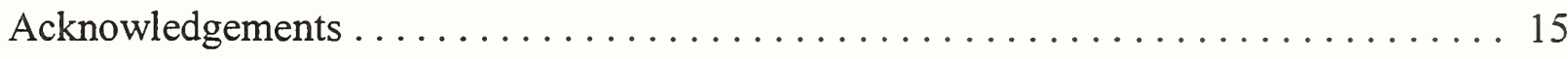

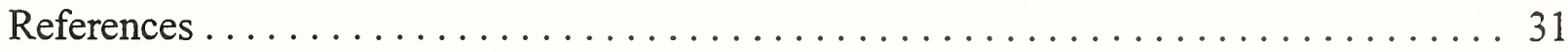


A.1 Differential Equation for Heat Conduction $\ldots \ldots \ldots \ldots \ldots \ldots \ldots \ldots$ A-1

A.2 Initial Condition and Boundary Condition $\ldots \ldots \ldots \ldots \ldots \ldots \ldots \ldots$ A-4

A.3 Semi-Infinite Rod, Initial Temperature Zero, Surface $z=0$

Maintained at Constant Temperature for $\mathrm{t}>0$.

A.4 Semi-Infinite Rod, Initial Heat Flux Zero, Surface $z=0$

Maintained at Constant Heat Flux for $t>0 \ldots \ldots \ldots \ldots \ldots$ A 6

A.5 Stress-Free Thermal Expansion $\ldots \ldots \ldots \ldots \ldots \ldots \ldots \ldots \ldots \ldots \ldots \ldots \ldots \ldots \ldots \ldots \ldots$

A.5.1 Basic Considerations ......................... A -8

A.5.2 Thermal Expansion for Constant Temperature Input . . . . . . . . . . . . A-9

A.5.3 Thermal Expansion for Constant Heat Flux Input . . . . . . . . . . . . A-10

References .................................. A-11

APPENDIX B $\quad$ Surface Cooling Details ......................

B.1 Estimation of the Convection Heat Transfer Coefficient, $h . . . . . . . . . .$. . B-1

References ..................................... 


\section{LIST OF FIGURES}

1. The NIST Octahedral Hexapod Machine Tool .................... 4

2. NIST Octahedral Hexapod Strut: Basic Dimensions .............. 5

3. NIST Octahedral Hexapod Strut: Dimensions Related to Strut Extension ...... 6

4. Heat Conduction/Transfer Model ......................... 16

5. Step Temperature Response: $20^{\circ} \mathrm{C}$ Step Input and $23^{\circ} \mathrm{C}$ Ambient

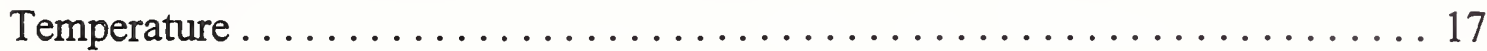

6. Contours of Constant Temperature for Step Temperature Response:

$20^{\circ} \mathrm{C}$ Step Input and $23^{\circ} \mathrm{C}$ Ambient Temperature . . . . . . . . . . . 18

7. Thermal Expansion for a Step Temperature Input: $20^{\circ} \mathrm{C}$ Step Input,

$23^{\circ} \mathrm{C}$ Ambient Temperature and $20^{\circ} \mathrm{C}$ Rod Calibration Temperature

8. Contours of Constant Thermal Expansion for a Step Temperature Input: $20^{\circ} \mathrm{C}$ Step Input, $23^{\circ} \mathrm{C}$ Ambient Temperature and $20^{\circ} \mathrm{C}$ Rod Calibration

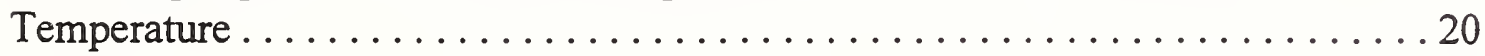

9. Step Heat Flux Response (Heat Flux Step Amplitude to Yield $20^{\circ} \mathrm{C}$ Asymptotic Temperature Rise) . . . . . . . . . . . . . . . . . . 21

10. Contours of Constant Heat Flux for Step Heat Flux Input ........... 22

11. Temperature Response to Step Heat Flux Input: Asymptotic $20^{\circ} \mathrm{C}$

Temperature Rise and $23^{\circ} \mathrm{C}$ Ambient Temperature .................. 23

12. Contours of Constant Temperature for a Step Heat Flux Input:

Asymptotic $20^{\circ} \mathrm{C}$ Temperature Rise and $23^{\circ} \mathrm{C}$ Ambient Temperature ....... 24

13. Thermal Expansion for a Step Heat Flux Input: Asymptotic $20^{\circ} \mathrm{C}$

Temperature Rise, $23^{\circ} \mathrm{C}$ Ambient Temperature, and $20^{\circ} \mathrm{C}$ Rod Calibration

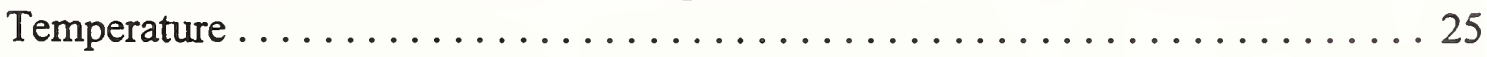

14. Contours of Constant Thermal Expansion for a Step Heat Flux Input:

Asymptotic $20^{\circ} \mathrm{C}$ Temperature Rise, $23^{\circ} \mathrm{C}$ Ambient Temperature, and $20^{\circ} \mathrm{C}$ Rod Calibration Temperature ............................ 26 
15. Contours of Constant Temperature Response for "Low" Cooling $\left(\lambda=1.2 \cdot 10^{-5} 1 / \mathrm{s}\right)$ Due to a Constant Step Heat Flux Input (Compare to Figures 12 and 17)...

16. Contours of Constant Thermal Expansion Response for "Low" Cooling $\left(\lambda=1.2 \cdot 10^{-5} 1 / \mathrm{s}\right)$ Due to a Constant Step Heat Flux Input (Compare to

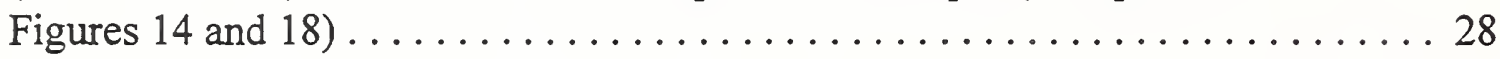

17. Contours of Constant Temperature Response for "High" Cooling $\left(\lambda=7.4 \cdot 10^{-4} 1 / \mathrm{s}\right)$ Due to a Constant Step Heat Flux Input (Compare to

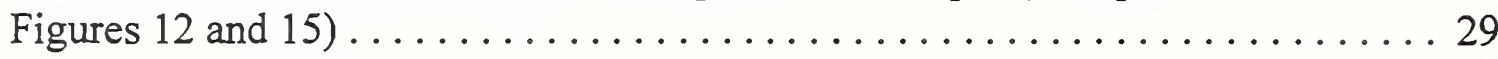

18. Contours of Constant Thermal Expansion Response for "High" Cooling $\left(\lambda=7.4 \cdot 10^{-4} 1 / \mathrm{s}\right)$ Due to a Constant Step Heat Flux Input (Compare to Figures 14 and 16)

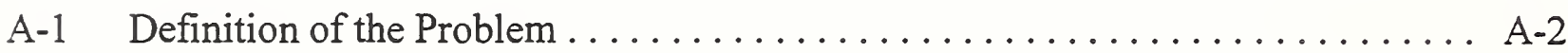

\section{TABLE}

B-1 Range of Parameters ................................. B-4 
SUMMARY: This report presents explicit analytical expressions for the thermal expansion of a rod with heat input at one end and forced convection cooling along the length of the rod. When the rod is graduated for length measurement (i.e., a ruler or ball screw), thermal expansion causes an error in the length measurement. For the problem described here, the thermal expansion or length error depends upon both distance along the rod and time. Calculations are presented illustrating the magnitude of the measurement error for representative conditions of heating and cooling.

The report considers two heat input models: step temperature input and step heat flux input. A representative example illustrates the system response to the two inputs. The detail calculations illustrate the differences between the two idealized input models. These idealized models are basis response functions that may be used to estimate system response to general time-varying heat input conditions. The implications for using these results for system metrology are discussed. 
Ball screws are a common mechanical system used to position an object. A ball nut is attached to the ball screw and as the ball screw is rotated the ball nut moves along the screw. The distance that the ball nut moves with each rotation is established by the constant pitch of the ball screw. The positioning accuracy of this system is, ideally, dependent upon the manufacturing precision of both the ball screw pitch and the matching ball nut. The ball screw and ball nut are manufactured and calibrated to establish the positioning accuracy of the system. This calibration is conducted under controlled conditions of temperature and low speed rotation of the ball screw to ensure calibration accuracy. The above considerations also apply to a graduated scale or ruler although in this instance no motion is involved.

When the ball screw-ball nut system is used in a mechanical system such as a machine tool, the operating conditions are quite different from the calibrated conditions. Although the machine tool may be independently calibrated to determine the positioning accuracy of the system, this calibration may not completely encompass the entire range of operating conditions of the machine. Temperature changes from the calibration conditions are commonly recognized as one of the more important factors affecting positioning accuracy during operation. The effect of temperature changes on the positioning accuracy of the ball screw-ball nut system is only one aspect of the more comprehensive (and complicated) problem for the entire machine.

Considerable design effort and expense is expended to provide a length measurement system for a machine tool that is independent of the ball screw-ball nut system. These systems require computer control of the machine positioning using the independent length measurement to control the motion. A scale-based metrology system may represent five percent of the machine cost and a laser-based metrology system may represent 25-35 percent of the machine cost. These costs are in addition to the computer control system. Cost considerations commonly result in computer control systems that use measurement of the ball screw rotation to infer the positioning assuming the constant calibrated pitch of the ball screw. This type of metrology system is currently used for strut length positioning of the NIST Octahedral Hexapod machine tool.

A motor is used to rotate the ball screw. The rated continuous power is, typically, several kilowatts. A ball screw-ball nut system is usually 90 percent efficient. That is, 90 percent of the motor power is transferred from the motor input to the ball nut to move the mechanical load. The ten percent loss in power at the ball screw-ball nut contact is friction in the system and the friction is exhibited as heat generation. The heat generated in the ball nut is transferred to both the machine attachment and the ball screw. This heat transfer causes the ball screw to expand and changes the ball screw pitch. The change in pitch results in errors in positioning. Based upon the efficiency of the system, the thermal power transferred to the ball screw may be on the order of a kilowatt.

The analysis described in this report is an approximation to the physical situations discussed above. The purpose of the analysis is two fold: a simulation model to estimate the temperaturedependent strut length errors of the NIST Octahedral Hexapod and ultimately the tool-tip 
positioning errors of the machine and to assist in the interpretation of ball screw temperature measurements on the operating machine.

\section{THE NIST OCTAHEDRAL HEXAPOD}

Figure 1 is a solid model representation of the NIST Octahedral Hexapod machine tool [1]. The tool spindle is supported by six struts. As described below, each strut is extended and retracted in a coordinated manner to position the tool tip for machining a part. The tool tip position and the orientation of the tool axis relative to the part is dependent upon the lengths of all the struts. The computer control of the machine utilizes data describing the calibrated geometry of the machine tool. This calibrated geometry comprises, in part, the locations in space of each end of each strut and the length of each strut for the "home" position of the machine tool. The calibrated geometry was established by the manufacturer upon the machine's assembly at NIST.

Figure 2 illustrates the strut geometry of the NIST Octahedral Hexapod. On the right end of this figure a large ball joint is illustrated ( $329 \mathrm{~mm}^{\text {diameter }}{ }^{1}$ ). This is the strut end supported by the octahedral frame of the machine tool. Rigidly attached to the large ball joint is the outer sleeve of the strut. As illustrated in Figure 3, the outer sleeve is $2062.4 \mathrm{~mm}$ long. An inner sleeve slides within the outer sleeve. The left hand end of the figure illustrates an $80 \mathrm{~mm}$ diameter ball joint. This ball joint is rigidly attached to the sliding inner sleeve and connects the strut to the platform supporting the tool spindle. As illustrated, the length of the sliding inner sleeve is $2037.4 \mathrm{~mm}$. Also illustrated in this figure at the right hand end of the sliding inner sleeve is a $260 \mathrm{~mm}$ long area denoted by an " $\mathrm{x}$ " symbol. This is the ball nut and it is rigidly attached to the inner sleeve. The sliding inner sleeve is keyed to the outer sleeve so that the inner sleeve cannot rotate with respect to the outer sleeve.

Figure 3 illustrates the strut in three configurations of strut extension. This extension is mechanically realized by rotating a ball screw which drives the ball nut. In Figures 2 and 3 the ball screw is illustrated by the $/ \%$ symbol. From the center of the large ball joint of the strut, the ball screw length is $1912.4 \mathrm{~mm}$. As indicated in Figure 3 (see notes in upper left hand corner), mechanical limitations result in a limited strut stroke of $1433 \mathrm{~mm}$.

The strut ball screw is driven by a mechanical coupling to a drive motor at the right hand end of the strut. The coupling and motor are not illustrated in Figures 2 and 3. Also, the location of the switches indicating the strut "home" position is not illustrated. These switches are located on the outer sleeve of the strut on the right hand side and towards the large ball joint. The strut "home" position is a configuration similar to that illustrated at the top of Figure 3.

For the NIST Octahedral Hexapod, the ball screw of each strut is manufactured with a $10 \mathrm{~mm}$ diameter hole (not shown) through the length of the ball screw. Also, the clearance hole continues through the coupling to the drive motor and the drive motor axis. The purpose of this hole is to allow for installation of a laser-based strut length metrology system for each strut.

${ }^{1}$ all dimensions are design values 

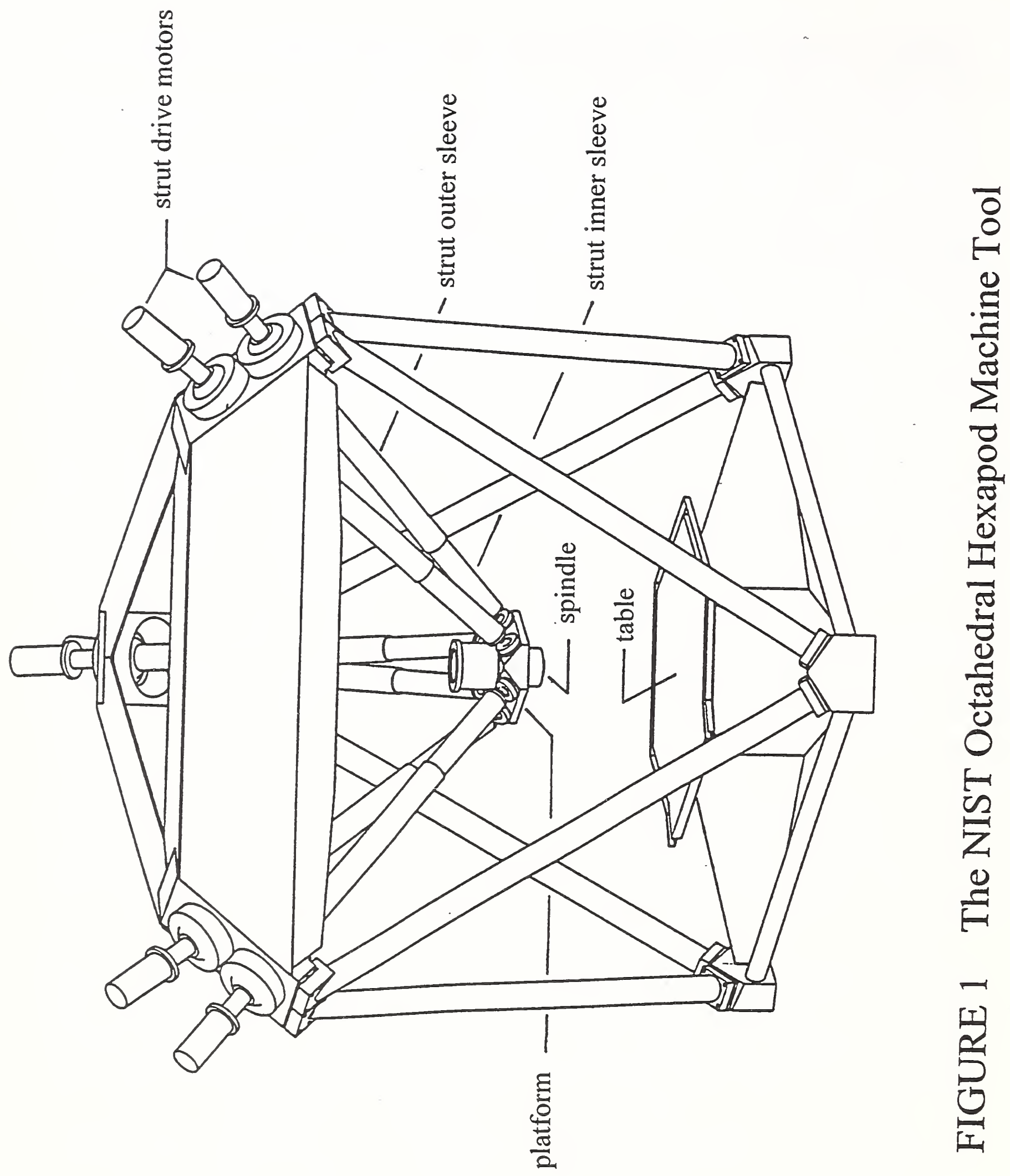


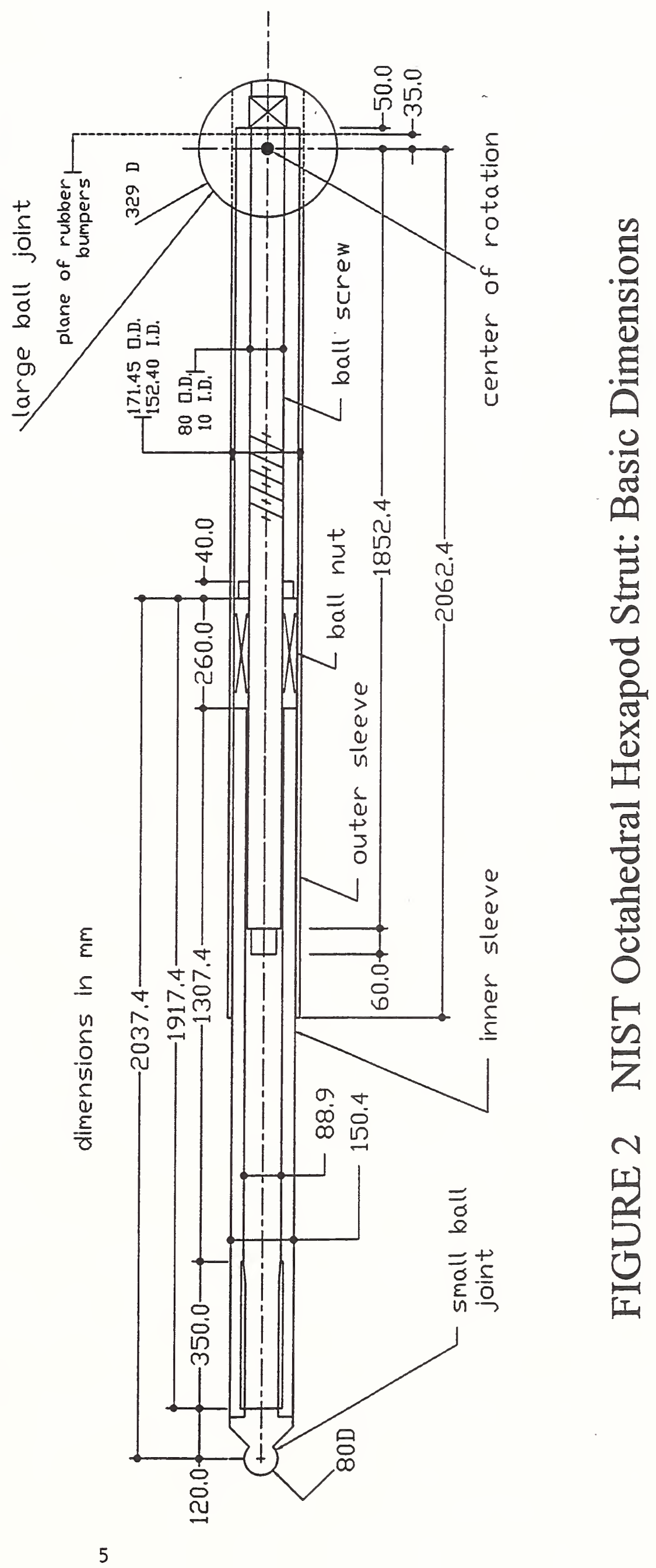



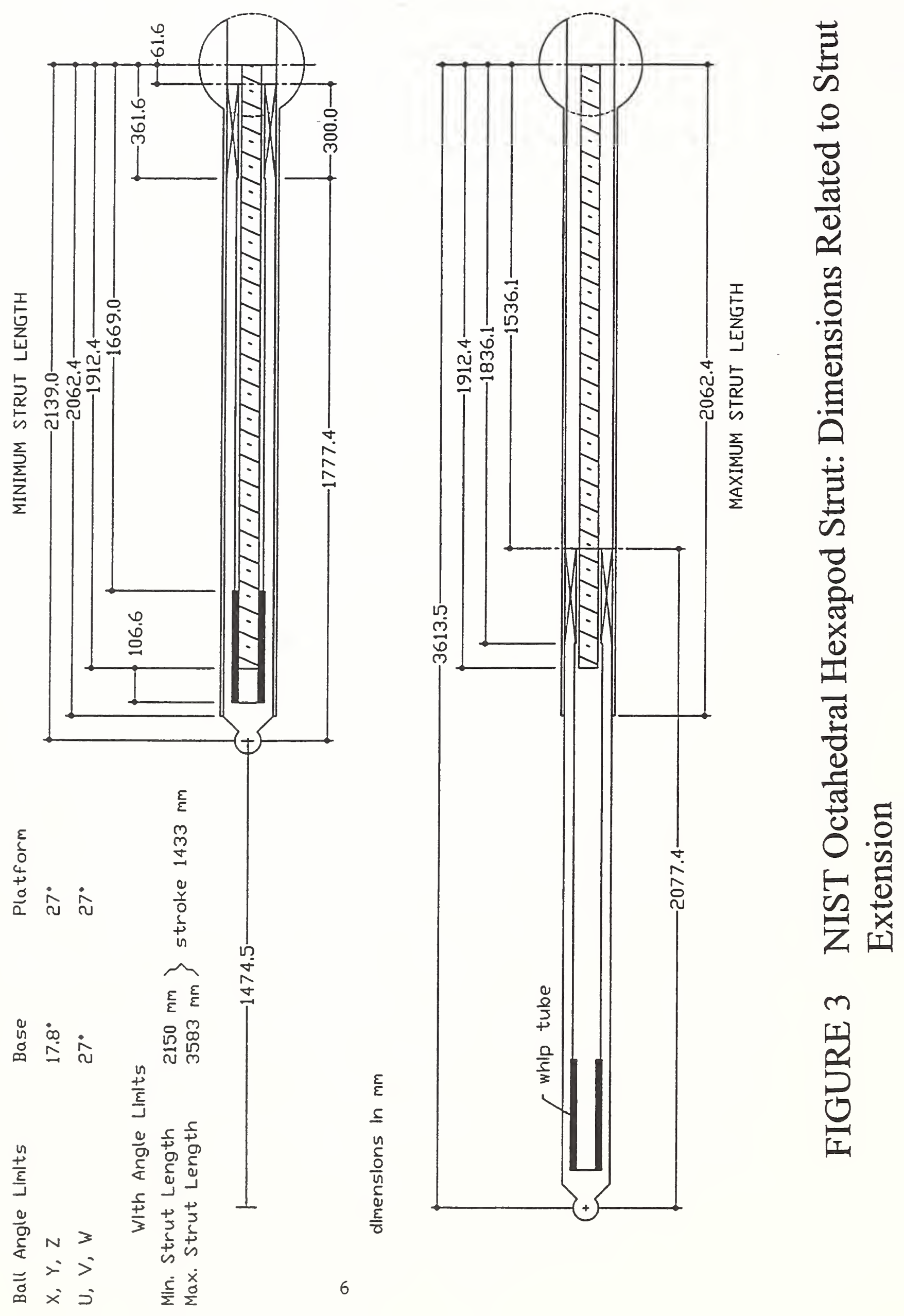
Presently, the strut length metrology is based upon a resolver fixed to the strut drive motor shaft and strut length is inferred from the motor rotation and the calibrated fixed pitch of the ball screw.

Friction of sliding contact is exhibited by heat generation. Three potentially significant sources of heat generation are evident in the strut configuration illustrated in Figures 2 and 3 . The sliding contact between the inner and outer sleeve of the strut results in heating of both components. This heating causes both components to experience a temperature change and thermal expansion which is both distance dependent (along the strut component) and time dependent. The sliding contact area between the inner sleeve and the outer sleeve is the first 400 $\mathrm{mm}$ measured from the left hand end of the outer sleeve. This thermal expansion may result in two sources of length error for the strut extension: expansion of the $2037.4 \mathrm{~mm}$ long inner sleeve and "drift" of the reference location of the "home" position switches fixed to the outer sleeve. For the present configuration, the computer control of the NIST Octahedral Hexapod is ignorant of these effects.

The second source of potential sliding contact heat generation is the swivel of the strut ball joints within their mechanical seats. For these joints, the rotation rates are rather lower in magnitude when compared to the strut extension rates. This aspect of the heat generation sources is not considered here.

The third potential source of heat generation is the ball nut friction. The heat generation within the rolling elements of the ball nut is transferred to both the sliding inner sleeve and the ball screw. The heat transferred to the inner sleeve will contribute to its thermal expansion in addition to the sliding contact with the outer sleeve. The ball nut heat transferred to the ball screw will result in thermal expansion of the ball screw. The thermal expansion of the ball screw results in a nonuniform change in the ball screw pitch. The nonuniformity is in both position along the ball screw and in time. The computer control of the NIST Octahedral Hexapod is also ignorant of these effects.

The NIST Octahedral Hexapod utilizes excellent machine tool design. Provisions are incorporated in the design to maintain well lubricated surfaces for all sliding components. The lubrication is provided to minimize the effects of heat generation by sliding contact. However minimal, the effects of thermal expansion must be quantified in order to characterize the tool-tip positioning of the machine. The present analysis is one step along the path to characterization of this machine tool configuration.

\section{HEAT CONDUCTION/TRANSFER MODEL}

The heat conduction/transfer model described in this report is illustrated in Figure $4^{2}$. Appendix A presents the mathematical details for obtaining analytical expressions for the temperature,

${ }^{2}$ Beginning with Figure 4, the figures are placed at the end of the text so as not to interrupt the commentary. 
$T(z, t)$, and the thermal expansion, $w(z, t)$, of the rod. Appendix B presents the details for estimating the forced convection heat transfer coefficient, $h$. The discussion here uses these results without explicity trudging through the mathematical details.

The mechanical system illustrated in Figure 4 is a one-dimensional ( $z$ is the dimension) heat conduction problem [2]. The temperature distribution, $\mathrm{T}(\mathrm{z}, \mathrm{t})$, must satisfy a partial differential equation subject to an initial condition (state of the system at time $t=0$ ) and a boundary condition (the heat input condition at $z=0$ ). The initial condition applies for all $z>0$ and the boundary condition applies for all $t>0$.

Once the expression for the temperature is obtained, the thermal expansion, $\mathrm{w}(\mathrm{z}, \mathrm{t})$, is obtained by integrating the expression for the temperature. This form of the thermal expansion is specifically a "stress free" expansion. That is, there are no constraints imposed on the rod to oppose the expansion.

Now, we discuss the two physical parameters that characterize both the temperature and thermal expansion of the rod. First, we consider the temperature and then the thermal expansion. To do this it is necessary to state the form of the governing partial differential equation.

The governing partial differential equation is derived in Appendix $\mathrm{A}$ and is given by $\mathrm{Eq}(\mathrm{A}-5 \mathrm{~b})$. The equation is:

$$
\kappa \frac{\partial^{2} T}{\partial z^{2}}-\lambda\left(T-T_{\infty}\right)=\frac{\partial T}{\partial t}: z>0 \text { and } t>0
$$

For this equation $T(z, t)$ is the temperature (solution of the equation) and is a function of the axial distance, $z$, and time, $t$. The parameters characterizing the problem are $\kappa, \lambda$, and $T_{\infty}$ which are assumed constant. As indicated in Figure 4, $\mathrm{T}_{\infty}$ is the constant ambient temperature of the air surrounding the rod and is the temperature used to specify the initial condition for Eq (1). Discussion will focus upon the two really important parameters: $\kappa$ and $\lambda$. These are dimensional parameters (i.e., their magnitude depends upon the physical units used to define mass, length, time and temperature).

The physical units used here are: mass in kilograms $(\mathrm{kg})$, length in meters $(\mathrm{m})$, time in seconds (s), and temperature in degrees Celsius $\left({ }^{\circ} \mathrm{C}\right)$. Each term in $\mathrm{Eq}(1)$ has the physical dimension of ${ }^{\circ} \mathrm{C} / \mathrm{s}$. As described in Appendix A, the first term in $\mathrm{Eq}(1)$ (the term containing $\mathrm{K}$ ) is the time rate of change of thermal energy due to heat conduction along the rod at the location $\mathrm{z}$ and time $\mathrm{t}$ of the system. The second term in $\mathrm{Eq}(1)$ (the term containing $\lambda$ ) is the time rate of change of thermal energy due to the dissipation of heat along the length of the rod. The right hand side of $\mathrm{Eq}(1)$ is the time rate of change of thermal energy at the location $\mathrm{z}$ and time $\mathrm{t}$ of the system.

The parameter $\kappa$ is called the thermal diffusivity and depends upon the material properties of the rod. The physical units of $\mathrm{K}$ are $\mathrm{m}^{2} / \mathrm{s}$. This parameter scales (i.e., relates) the spatial coordinate $z$ (m) and the temporal coordinate $\mathrm{t}(\mathrm{s})$. 
The parameter $\lambda$ is called the cooling coefficient and it is directly proportional to the convection heat transfer coefficient, $h$, and is also a function of the cross-section shape of the rod and the material properties of the rod (see Eq (A-5)). This is a dissipation rate and has physical dimensions of $1 / \mathrm{s}$. This parameter scales the temporal coordinate, t. The parameter $\lambda$ characterizes the time constant for the temperature variation of the system.

The parameter $\sqrt{(\lambda / \kappa)}$ has physical dimension $1 / \mathrm{m}$. As indicated in the rather complicated expressions for temperature given in Appendix A, the parameter $\sqrt{ }(\lambda / \kappa)$ characterizes the spatial constant for the temperature variation.

Appendix $B$ describes the steps necessary to estimate the parameter $\lambda$ and presents the ranges of the magnitudes of the parameters characterizing the problem. For a circular cross section steel rod cooled by low velocity air flow at atmospheric temperature and pressure, the ranges of magnitude of $\kappa$ and $\lambda$ are:

and

$$
1 \cdot 10^{-6} \mathrm{~m}^{2} / \mathrm{s}<\mathrm{\kappa}<2 \cdot 10^{-6} \mathrm{~m}^{2} / \mathrm{s}
$$

$$
1.2 \cdot 10^{-5} 1 / \mathrm{s}<\lambda<7.2 \cdot 10^{-4} 1 / \mathrm{s} \text {. }
$$

From these ranges one may infer the range of the spatial constant as:

$$
2.451 / \mathrm{m}<\sqrt{(\lambda / \kappa)}<26.81 / \mathrm{m} \text {. }
$$

The constants $\lambda$ and $\sqrt{ }(\lambda / \kappa)$ indicate that temperature changes occur over several thousands of seconds (i.e. hours) and over distances of less than one meter, for the stated conditions.

The thermal expansion, $\mathrm{w}(\mathrm{z}, \mathrm{t})$, is characterized by the above parameters and an additional parameter, $\alpha$ : the coefficient of thermal expansion. The physical dimensions of $\alpha$ are $\mathrm{m} / \mathrm{m}^{\circ} \mathrm{C}$ or $1 /{ }^{\circ} \mathrm{C}$. For steels used in precision machines [3] the range of the coefficient of thermal expansion is:

$$
\text { almost zero }<\alpha<18 \cdot 10^{-6} 1 /{ }^{\circ} \mathrm{C} \text {. }
$$

For a ball screw, the upper limit for $\alpha$ is more typical. Measuring thermal expansion in micrometers $(\mu \mathrm{m})$ it is seen that a few degress Celsius change in temperature can result in a significant thermal expansion. Since the thermal expansion involves the integral of the temperature, local changes in temperature along the rod result in larger cumulative displacements (i.e., position errors) along the rod.

Example calculations illustrate the above comments.

\section{EXAMPLE CALCULATIONS}

Appendix A presents the mathematical expressions for the temperature, $T(z, t)$, and thermal expansion, $w(z, t)$, of the rod. These expressions assume an initial temperature of the rod at the ambient temperature of the air (the initial condition for $\mathrm{Eq}(1)$ ). Two physical forms of the heat 
input to the rod are considered: constant temperature input and constant heat flux input. These are the two boundary conditions for $\mathrm{Eq}(1)$. Hence, two problems are considered: constant temperature input and constant heat flux input. This form of input is denoted mathematically as a step function input. The resulting expressions for temperature and thermal expansion of the rod are the step response functions of the system. These step response functions may be used to obtain temperature and thermal expansion for more complicated heat input conditions than those considered in this report [4].

The actual heat input to a ball screw in contact with a moving ball nut is (as an understatement) a very complicated problem. In the present discussion, the two physical forms of heat input are considered since the actual input may never be either measurable or known. What can be measured are temperatures at a distance away from the input and overall thermal expansion (position errors) of the system. Hence, the results in this report can, at best, assist in the interpretation of experimental data.

\section{PARAMETERS FOR EXAMPLE CALCULATIONS}

As described above, the two parameters defining the spatial and temporal characteristics are $\kappa$ and $\lambda$. To establish the amplitude of the system step response it is necessary to specify the initial ambient temperature and the magnitude of the heat input.

For illustration, the rod is assumed to be 303 stainless steel at an initial temperature of $23^{\circ} \mathrm{C}$ and atmospheric pressure. The diameter of the rod is $80 \mathrm{~mm}$ and the cooing air velocity is $0.1 \mathrm{~m} / \mathrm{s}$. For the thermal expansion, it is assumed that the rod scale (i.e., ball screw pitch) is calibrated at $20^{\circ} \mathrm{C}$. Hence, the rod in its initial state of $23^{\circ} \mathrm{C}$ exhibits a thermal expansion due to the $3^{\circ} \mathrm{C}$ temperature change between the scale calibration temperature and the ambient temperature.

The data for the calculations are [3]:

$$
\begin{aligned}
& \kappa=4.1 \cdot 10^{-6} \mathrm{~m}^{2} / \mathrm{s} \\
& \lambda=5.0 \cdot 10^{-5} 1 / \mathrm{s} \\
& \alpha=17.2 \cdot 10^{-6} 1 /{ }^{\circ} \mathrm{C} \\
& \text { ambient temperature }=23^{\circ} \mathrm{C} \\
& \text { calibration temperature }=20^{\circ} \mathrm{C} \\
& \text { step temperature input }=20^{\circ} \mathrm{C} \\
& \text { step heat flux input }=1131.6 \mathrm{~W} / \mathrm{m}^{2}
\end{aligned}
$$

The value for the step heat flux input is specified so that the asymptotic temperature rise at $\mathrm{z}=0$ for constant heat flux input is $20^{\circ} \mathrm{C}$. (See $\mathrm{Eq}(\mathrm{A}-14)$ and the limiting expressions for the temperature rise.) Also, the thermal conductivity of 303 stainless steel, $\mathrm{k}$, is $16.2 \mathrm{~W} / \mathrm{m}^{\circ} \mathrm{C}$. The magnitude of the step response inputs are taken only for illustration and result in a final (or asymptotic) temperature of $43^{\circ} \mathrm{C}$. 


\section{STEP RESPONSE FOR CONSTANT TEMPERATURE INPUT}

The temperature is a function of distance along the rod and time. Figure 5 is a three dimensional plot of the temperature as a function of distance along the rod in meters and time in minutes. The distance scale covers the range $0 \mathrm{~m}$ to $0.250 \mathrm{~m}$. The time scale covers the range 0 minutes to 480 minutes ( 8 hours). The constant temperature of $23^{\circ} \mathrm{C}$ along the plane $t=0$ minutes is the initial temperature of the rod. Considering the plane $z=0$, it is seen that the constant temperature input of $20^{\circ} \mathrm{C}$ is realized immediately and remains constant as time increases. The final temperature of the system at $\mathrm{z}=0$ is $\left(23^{\circ} \mathrm{C}+20^{\circ} \mathrm{C}\right) 43^{\circ} \mathrm{C}$.

Considering the plane $t=480$ minutes ( 8 hours), the temperature distribution along the length of the rod exhibits an exponential decay. (See the limiting expressions for temperature following $\mathrm{Eq}(\mathrm{A}-11)$.) The spatial decay rate for this example is $\sqrt{ }(\lambda / \mathrm{k})=3.49 \mathrm{1} / \mathrm{m}$. That is, after steady temperatures are realized (very large times), at $\mathrm{z}=1 / 3.49=0.286 \mathrm{~m}$ the temperature has decreased by a factor of $\mathrm{e}^{-1}=0.37$ or $\Delta \mathrm{T}=0.37(20)=7.4^{\circ} \mathrm{C}$ above ambient temperature.

Considering the plane $\mathrm{z}=0.250 \mathrm{~m}$, the temperature rise exhibits a smooth exponential-like increase once significant thermal energy reaches this location. The explicit functional form is given by $\mathrm{Eq}(\mathrm{A}-11)$. The time constant for this example is $1 / \lambda=20,000$ seconds ( 333.3 minutes).

Figure 6 presents contours of constant temperature as a function of distance along the rod and time. This figure indicates that the rod never realizes a constant temperature distribution along its length. This is expected since the rod is cooled along its length.

Figure 7 is the step response of the thermal expansion for a constant temperature input. The thermal expansion is measured relative to the plane $z=0$ and is, by definition, zero at $z=0$. The plane $t=0$ is the thermal expansion at an instant before the step temperature input is applied. The constant increase in thermal expansion is due to the $3^{\circ} \mathrm{C}$ temperature difference between the ambient temperature of the system and the assumed calibration temperature of the rod. (For computational reasons, the initial time illustrated in Figure 7 is 0.1 minutes.)

Figure 8 is a contour plot of constant thermal expansion as a function of distance along the rod and time. This figure illustrates that after 480 minutes of heating the first $200 \mathrm{~mm}$ of rod are approaching steady (time independent) conditions. Beyond $200 \mathrm{~mm}$ of rod length, the thermal expansion is slowly changing. For the first 60 minutes of heating, Figure 8 indicates that the thermal expansion is dominated by the $3^{\circ} \mathrm{C}$ temperature difference between the ambient temperature and the calibration temperature. This illustrates the importance of calibrating a machine tool in the ambient environment that it will be operated or making real-time correction for this error.

\section{STEP RESPONSE FOR CONSTANT HEAT FLUX INPUT}

As described in Appendix A, the heat flux is a function of distance along the rod and time. The heat flux satisfies the same partial differential equation as does the temperature, $\mathrm{Eq}(1)$. For the rod initially at the uniform ambient temperature, the initial heat flux is zero. The step increase of 
a constant heat flux input is mathematically identical to the constant temperature input discussed above. Hence, the functional form for the heat flux step response is identical to the temperature step response relative to the constant ambient temperature.

Figure 9 is a three dimensional plot of heat flux response for the constant heat flux input of $1131.6 \mathrm{~W} / \mathrm{m}^{2}$. The magnitude of the input is selected for illustration so that the reader may easily compare the step temperature response and the step thermal expansion response for heat flux input to the results (Figures 5 through 8 ) for constant temperature input. Comparing Figures 5 and 9 , it is seen that the shape of the surfaces is the same. All of the discussion for Figure 5 concerning time constants, spatial decay and limiting conditions are applicable to Figure 9.

Figure 10 is a constant contour plot of heat flux as a function of distance along the rod and time. This result is comparable to Figure 6 for the temperature step response.

For the step heat flux input, the temperature response is obtained by integrating the heat flux with respect to the spatial coordinate $z$ (see Eq (A-13)). This step is necessary since the heat flux is proportional to the spatial temperature gradient. The proprotionality constant is the thermal conductivity, $\mathrm{k}$, of the rod material. For this example, $\mathrm{k}=16.2 \mathrm{~W} / \mathrm{m}^{\circ} \mathrm{C}$.

Figure 11 is the temperature response of the rod due to the step heat flux input. This result should be compared to Figure 5 for the step temperature input. For the plane $z=0$, the step heat flux input causes a gradual temperature rise from the ambient temperature. For the plane $z=$ $0.250 \mathrm{~m}$, the temperature rise is also gradual and is similar to that illustrated in Figure 5. The explicit functional form is given by $\mathrm{Eq}(\mathrm{A}-14)$. For the plane $\mathrm{t}=480$ minutes, the temperature response is a spatial decay along the length of the rod and is functionally identical to that discussed for Figure 5. That is, after the steady temperature condition has been realized at $z=0$, the spatial temperature distribution along the rod is identical for both step temperature input and step heat flux input.

Figure 12 presents contours of constant temperature response due to the step heat flux input. This result should be compared with Figure 6 for the step temperature input. Hence, it is seen that the temperature change along the rod for any time is more gradual than that for the step temperature input. Although the data for this example was selected so that the temperature rise would asymptotically reach $43^{\circ} \mathrm{C}$ at $z=0$, it is seen in Figure 12 that after 480 minutes the temperature response has not reached its limiting value.

Figure 13 is the thermal expansion response of the rod due to the step heat flux input. This result should be compared to Figure 7 for the step temperature input. The comparison illustrates that the thermal expansion is more gradual for the step heat flux input as compared to the step temperature input. This is to be expected since the temperature response is more gradual when compared to the step temperature input. The increasing thermal expansion at time $t=0$ results from the $3{ }^{\circ} \mathrm{C}$ temperature difference between the $23^{\circ} \mathrm{C}$ ambient temperature and the $20^{\circ} \mathrm{C}$ rod calibration temperature assumed for this example. 
Figure 14 is a plot of contours of constant thermal expansion as a function of distance along the rod and time due to the step heat flux input. This result should be compared with Figure 8 for the step temperature input. For the step heat flux input, the contours of constant thermal expansion are more gradual both in distance along the rod and in time as compared to the step temperature input. As indicated in Figure 14, after 480 minutes of heating, steady state conditions are still not realized.

\section{LIMITING COOLING CONDITIONS}

The cooling parameter, $\lambda$, is the time rate of heat dissipation per unit length of the rod. For a circular cross section steel rod cooled by low velocity air flow at atmospheric temperature and pressure, the numerical range for $\lambda$ is:

$$
1.2 \cdot 10^{-5} 1 / \mathrm{s}<\lambda<7.2 \cdot 10^{-4} 1 / \mathrm{s}
$$

It is instructive to calculate the thermal expansion corresponding to the extreme values of this range. For this example the data are taken as described previously for constant heat flux input (Figures 9 through 14). The only change is the value of $\lambda$. Two values of $\lambda$ are discussed:

$$
\text { Low Cooling: } \lambda_{\text {low }}=1.2 \cdot 10^{-5} 1 / \mathrm{s}
$$

and

$$
\text { High Cooling: } \lambda_{\text {high }}=7.4 \cdot 10^{-4} 1 / \mathrm{s} \text {. }
$$

For each of these cases, two results are discussed: the temperature response of the rod and the thermal expansion of the rod. These results should given the reader an appreciation of the possible significance of cooling effects as estimated by the model. For the results presented in Figures $9-14$, the cooling rate is $\lambda=5.0 \cdot 10^{-5} 1 / \mathrm{s}$.

For low cooling, Figure 15 is the plot of contours of constant temperature for distance along the rod and time. Figure 15 should be compared to Figure 12. Two differences are evident between Figure 12 and Figure 15: The temperature distribution along the rod at fixed time and the asymptotic temperature at the rod end $(z=0)$. Figure 15 corresponds to a lower cooling rate as compared to Figure 12. Hence, at any time following initiation of heat flux input, the temperature distribution along the rod length is larger in magnitude in Figure 15 than in Figure 12. For Figure 15 , the asymptotic temperature exceeds $45^{\circ} \mathrm{C}$ (for Figure 12 , the heat flux input was selected to result in a $20^{\circ} \mathrm{C}$ temperature rise above ambient). The asymptotic temperature rise above ambient is given by the expression for $\mathrm{T}^{*}$ in $\mathrm{Eq}(\mathrm{A}-14 \mathrm{e})$. For the cooling rate $1.2 \cdot 10^{-5}$ of Figure 15 , the asymptotic temperature rise is $40.8^{\circ} \mathrm{C}$ above ambient $\left(63.8^{\circ} \mathrm{C}\right.$ total for an ambient temperature of $23^{\circ} \mathrm{C}$ ). This illustrates that for a constant heat flux input and low cooling, the temperature distribution along the rod is distinctly different from a more "typical" condition as illustrated in Figure 12. 
Figure 16 is the plot of contours of constant thermal expansion corresponding to the "low" cooling temperature distribution of Figure 15. The thermal expansion contours of Figure 16 should be compared with the contours of Figure 14. In this comparison, the reader should recognize that the thermal expansion is more severe for the for the lower cooling rate illustrated in Figure 16.

Now, we consider a high cooling rate corresponding to $\lambda=7.4 \cdot 10^{-4} 1 / \mathrm{s}$. This rate corresponds to a much higher velocity forced air cooling than previously described. The feasibility of achieving such a high cooling rate is, perhaps, unrealistic. However, the purpose here is to illustrate extreme effects.

Figure 17 is the plot of contours of constant temperature for $\lambda=7.4 \cdot 10^{-4} 1 / \mathrm{s}$. This plot should be compared to Figures 12 and 15 . Figure 17 illustrates a very dramatic difference in temperature response. First, for this "high" cooling example, steady state temperature distribution is achieved within 120 minutes of initiation of heat flux input, and the ambient $\left(23^{\circ} \mathrm{C}\right)$ temperature is realized for rod locations within approximately $0.3 \mathrm{~m}$ from the heat input. Additionally, the asymptotic temperature rise for the rod is $5.3^{\circ} \mathrm{C}$ above ambient rather than the $20^{\circ} \mathrm{C}$ rise for Figure 12 and the $40.8^{\circ} \mathrm{C}$ for Figure 15. For each of these results, the reader is reminded that the input heat flux is constant at $1131.6 \mathrm{~W} / \mathrm{m}^{2}$.

Figure 18 is the plot of contours of constant thermal expansion for the temperature response of Figure 17. The response illustrated in Figure 18 should be compared with the results of Figures 14 and 16. The "high" cooling response illustrated in Figure 18 is also dramatically different from the thermal expansion response illustrated in Figures 14 and 16. Figure 18 illustrates that steady state conditions are realized within the first 120 minutes of initiating the constant heat flux input. Further, for a fixed location along the rod, the thermal expansion for "high" cooling (Figure 18) is approximately 1/4 the thermal expansion for "low" cooling (Figure 16).

In summary, Figures 15 and 16 illustrate temperature and thermal expansion response, respectively, for "low" cooling along the rod length. Figures 17 and 18 are the corresponding response characteristics for "high" cooling. For both cases, the illustrated response is a result of a step heat flux input to the rod of constant magnitude.

\section{REALITY CHECK}

The above results are illustrations of an idealized system response to two different input functions. These results are based upon calculations utilizing complicated mathematical expressions. The question as to the reality of either input function remains open. Physically, it is the author's opinion that the step heat flux model is closer to reality than the step temperature input model.

This opinion is based upon energy considerations. To physically realize a constant temperature input, one must initially supply an infinite amount of power or energy to the system and gradually decrease this input to match the energy dissipated to cooling while maintaining the temperature at $z=0$ constant. This is impossible. 
A constant heat flux input implies a constant power or energy source. How this may be realized mechanically or measured in reality is also an open question. However, since the implication is a finite heat source, the author concludes that the step heat flux input is a more realistic condition.

Mathematically, knowing the step input response of a system allows one to compute the response to arbitrary time dependent inputs [4]. In this sense, either model may be appropriate although the author still learns towards the step heat flux input model. Response to an arbitrary time dependent input apparently requires the numerical integration of the complicated mathematical expressions given in Appendix A. Either approach requires the reality of metrology of the system response.

\section{METROLOGY CONSIDERATIONS}

As mentioned above, an infinite supply of energy is impossible. This implies that a constant step temperature input condition is impossible. From a metrology standpoint, the measurement of heat flux for mechanical contact of two surfaces is only slightly less than impossible. Measurement of temperature, especially under time-varying conditions, is rather easily accomplished.

The results described in this report are a guide to the conduct of metrology experiments and the interpretation of the experimental data. On the negative side one may not be aware of details of the heat input. On the positive side one has at least a few minutes to acquire metrology data with the knowledge that the conditions are not significantly changing with time.

\section{ACKNOWLEDGEMENTS}

During the course of completing the reported work, the author received numerous helpful comments and suggestions and direct assistance from the NIST staff. Dr. W. Tyler Estler and Dr. Howard Harary were very generous in their suggestions, comments, and loan of reference material to the author. Ms. Ellen Zeff very patiently typed and revised the entire manuscript. Mr. Joe Falco provided the Figure 1 illustration of the NIST Hexapod and Mr. David Ward prepared the illustrations in Figures 2 and 3. The draft manuscript was reviewed by Dr. Steven Phillips and Dr. Mahn Hee Hahn with their comments and suggestions incorporated in to the final report. Any undetected typographical or other errors are the author's responsibility. 


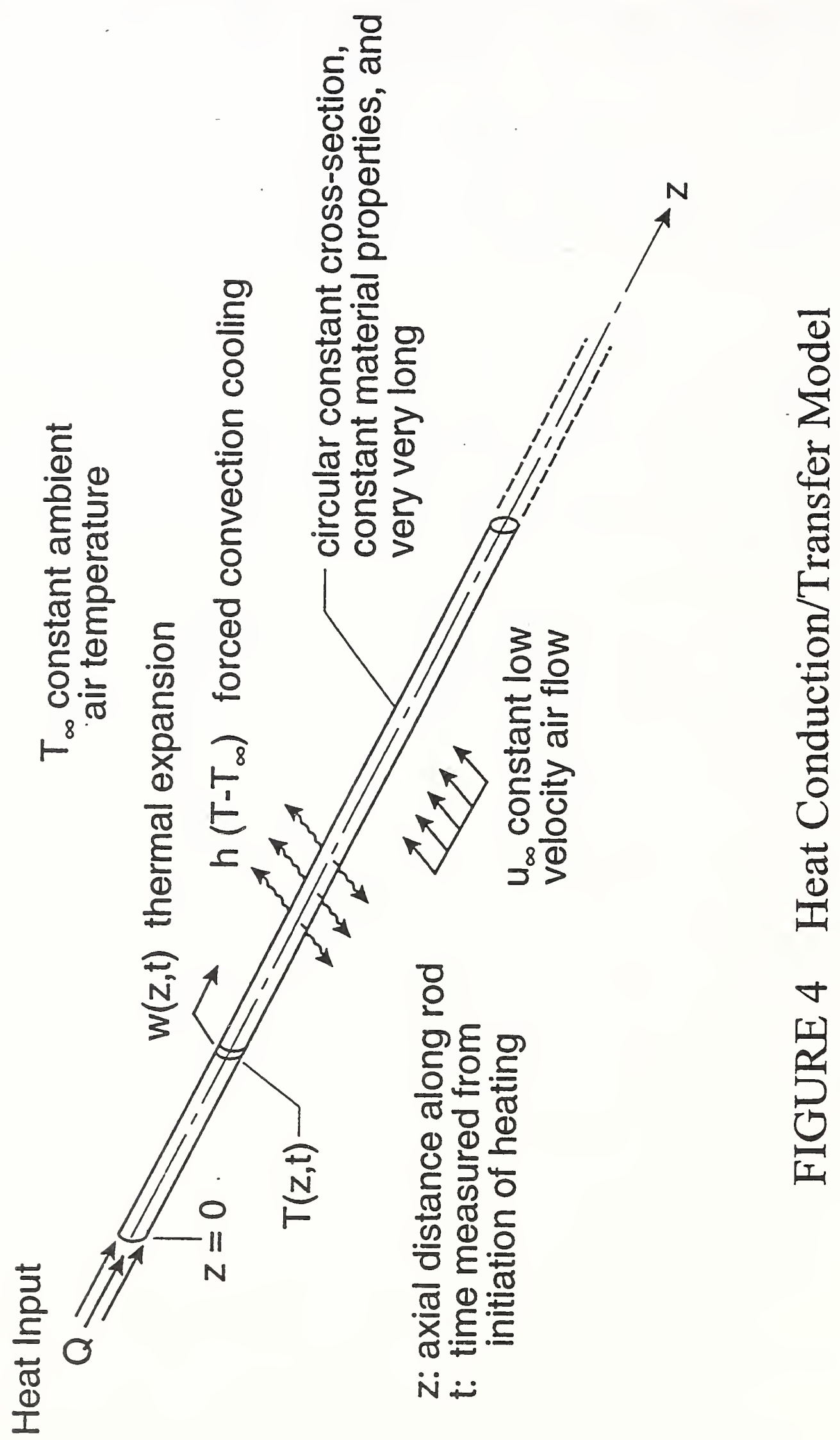




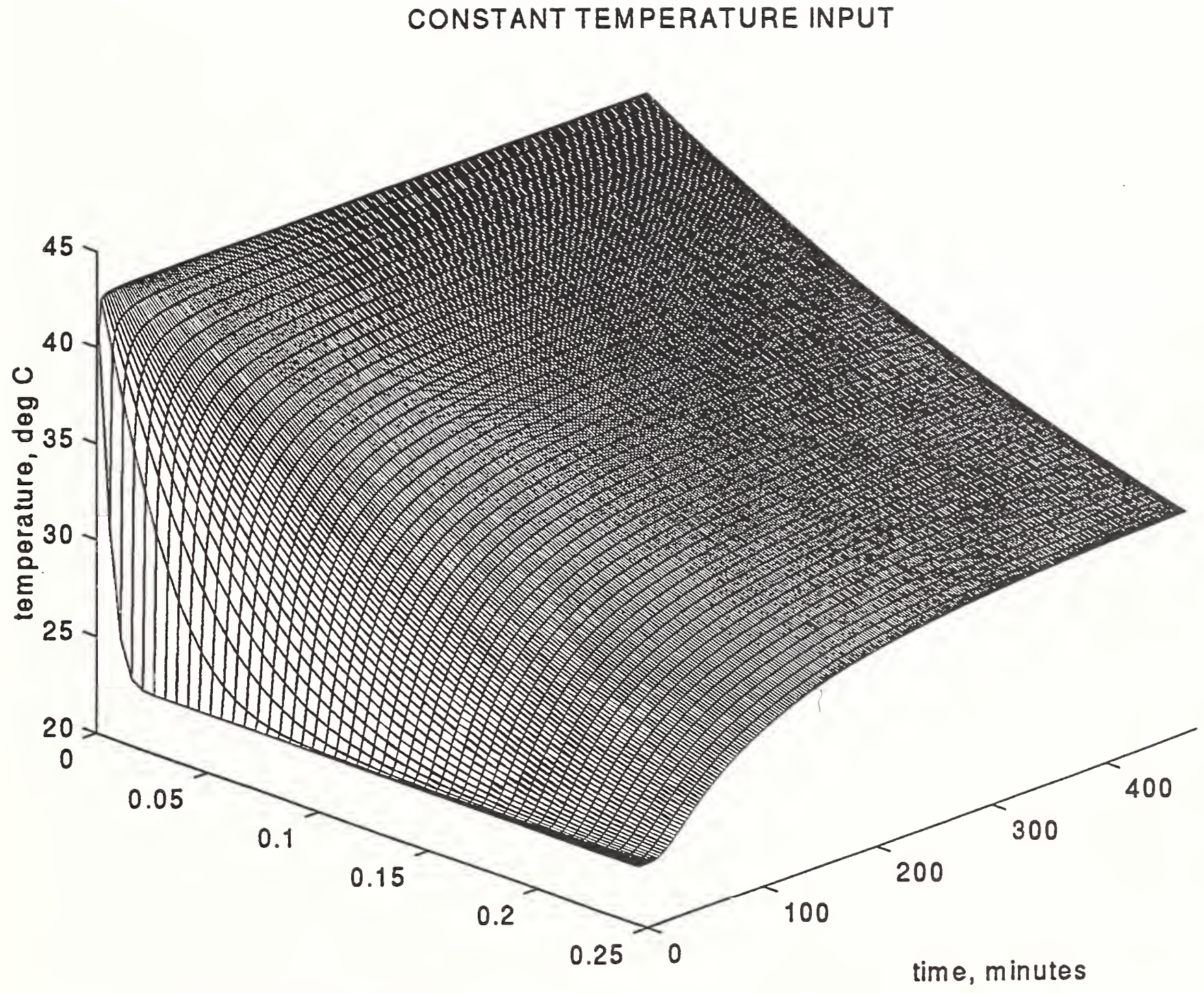

distance along rod, $m$

FIGURE 5 Step Temperature Response: $20^{\circ} \mathrm{C}$ Step Input and $23^{\circ} \mathrm{C}$ Ambient Temperature 


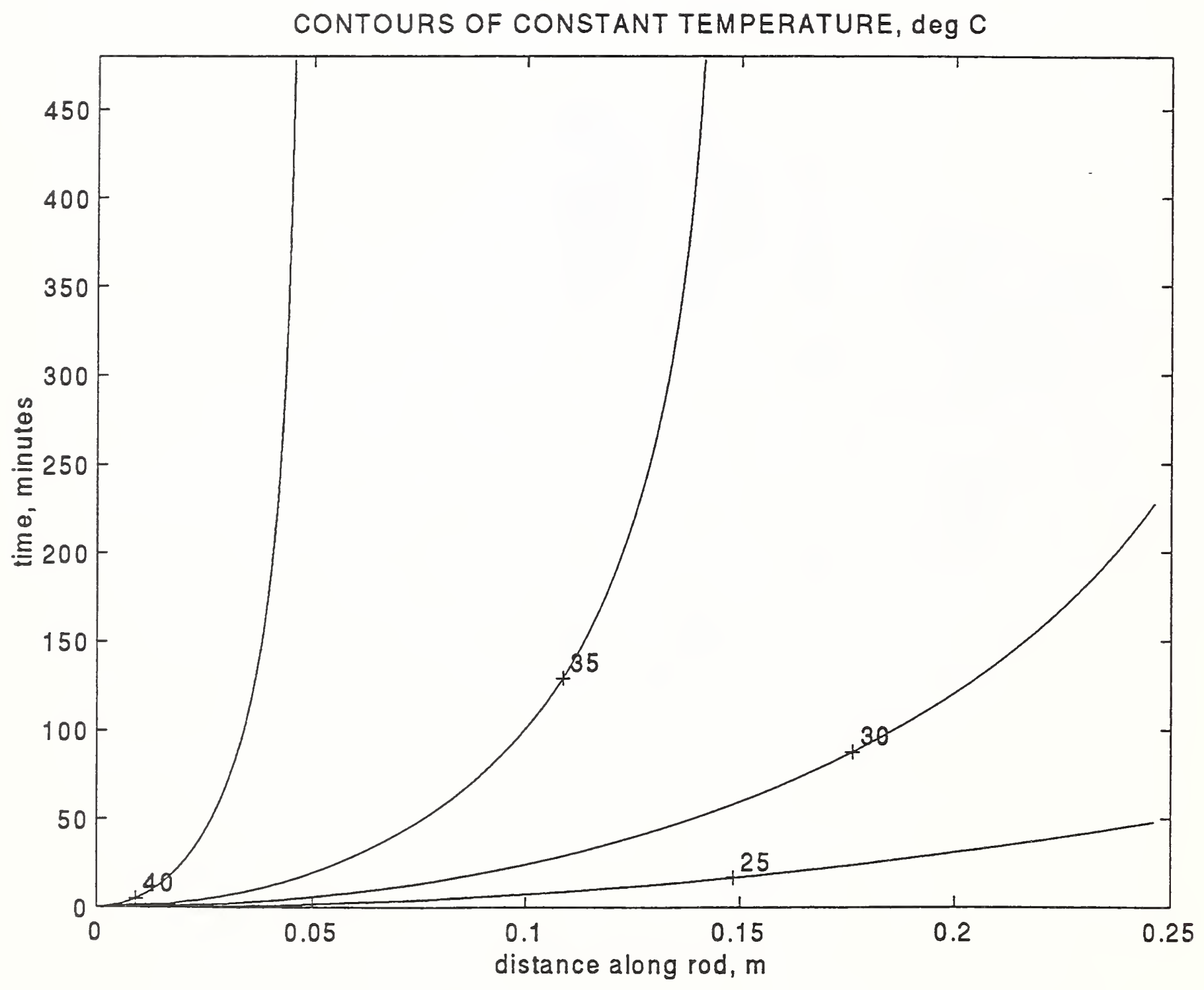

FIGURE 6 Contours of Constant Temperature for Step Temperature Response: $20^{\circ} \mathrm{C}$ Step Input and $23^{\circ} \mathrm{C}$ Ambient Temperature 
CONSTANT TEMPERATURE INPUT

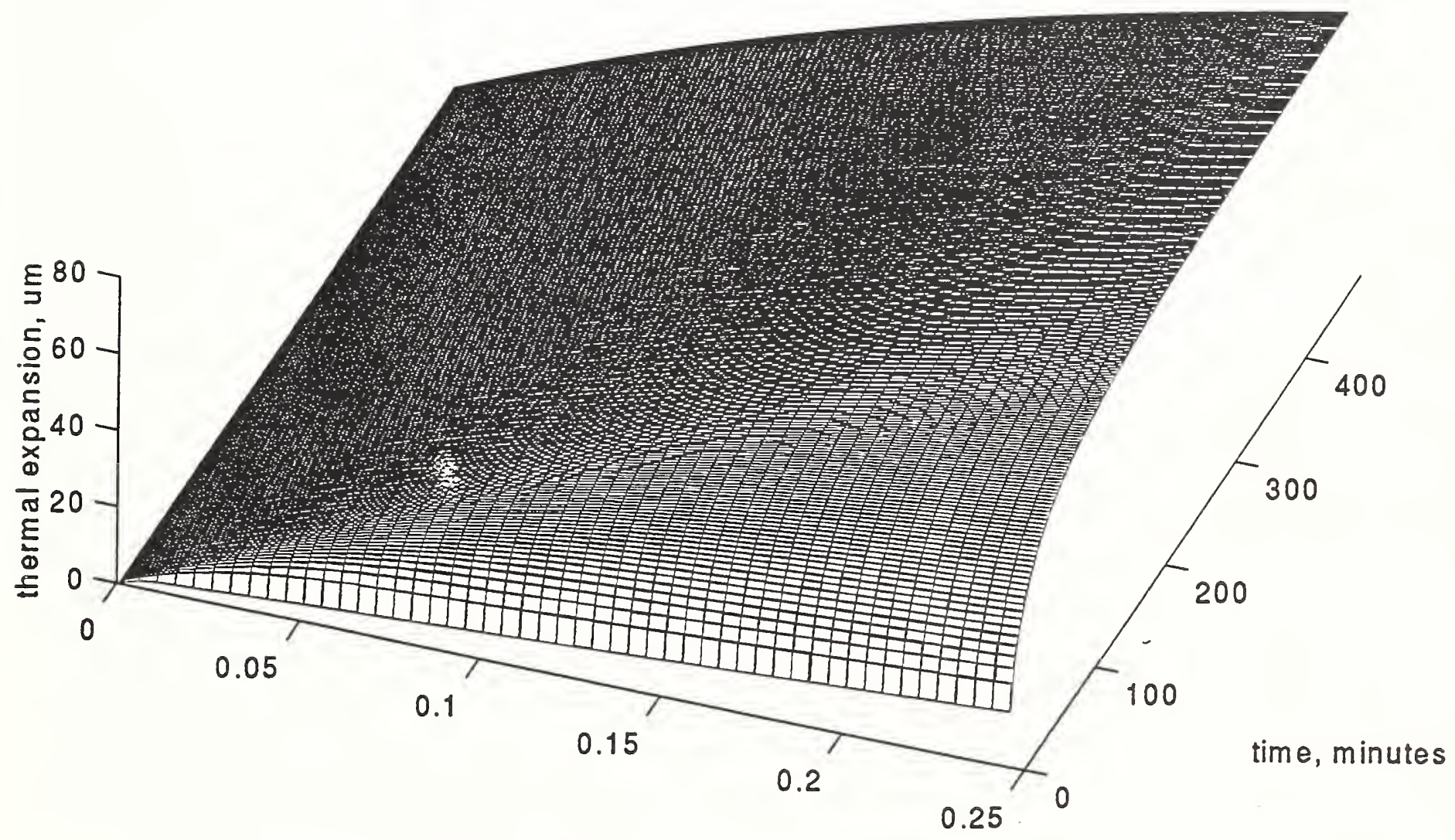

distance along rod, $m$

FIGURE 7 Thermal Expansion for a Step Temperature Input:

$20^{\circ} \mathrm{C}$ Step Input, $23^{\circ} \mathrm{C}$ Ambient Temperature and $20^{\circ} \mathrm{C}$ Rod Calibration Temperature 


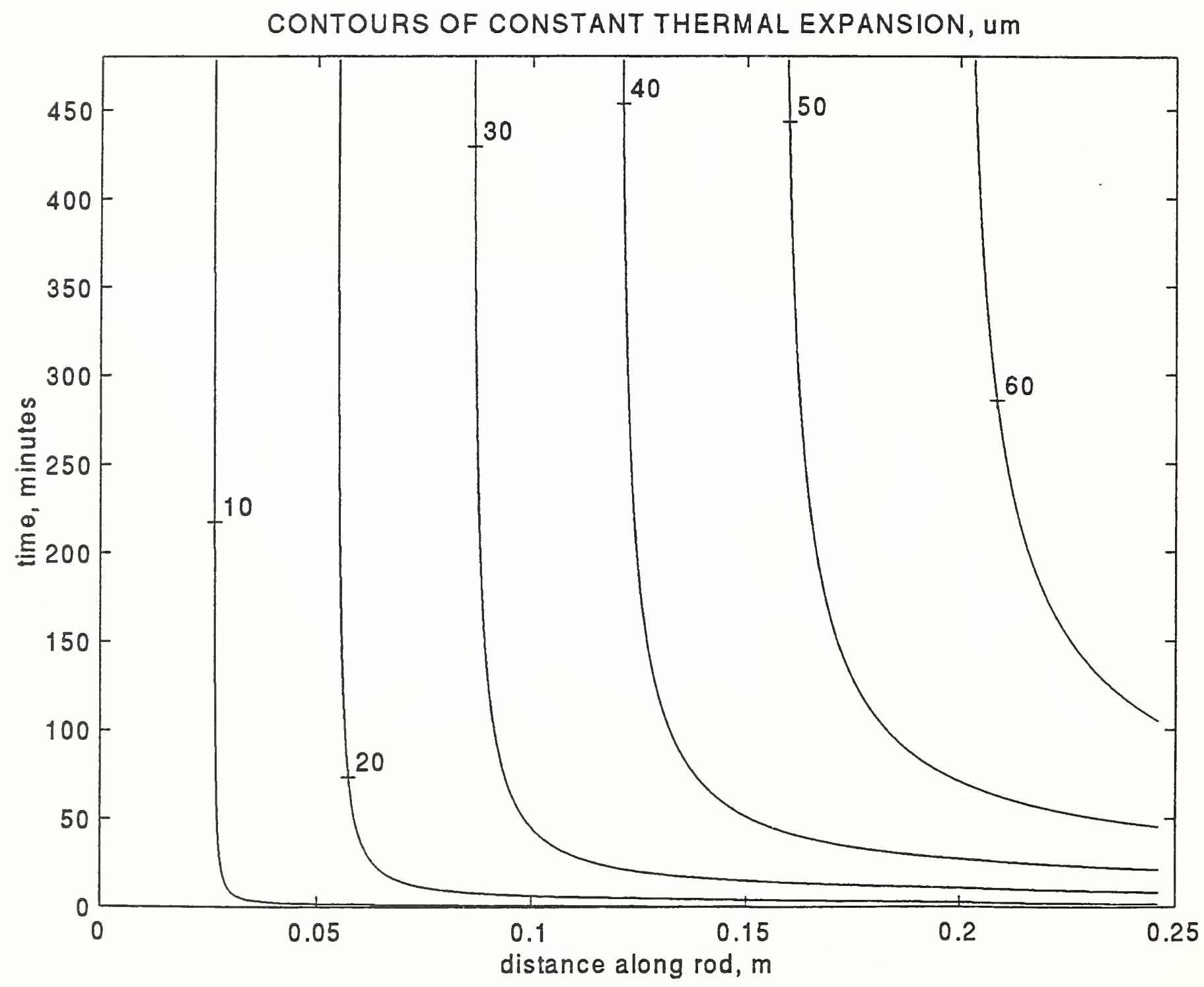

FIGURE 8 Contours of Constant Thermal Expansion for a Step Temperature Input: $20^{\circ} \mathrm{C}$ Step Input, $23^{\circ} \mathrm{C}$ Ambient Temperature and $20^{\circ} \mathrm{C}$ Rod Calibration Temperature 


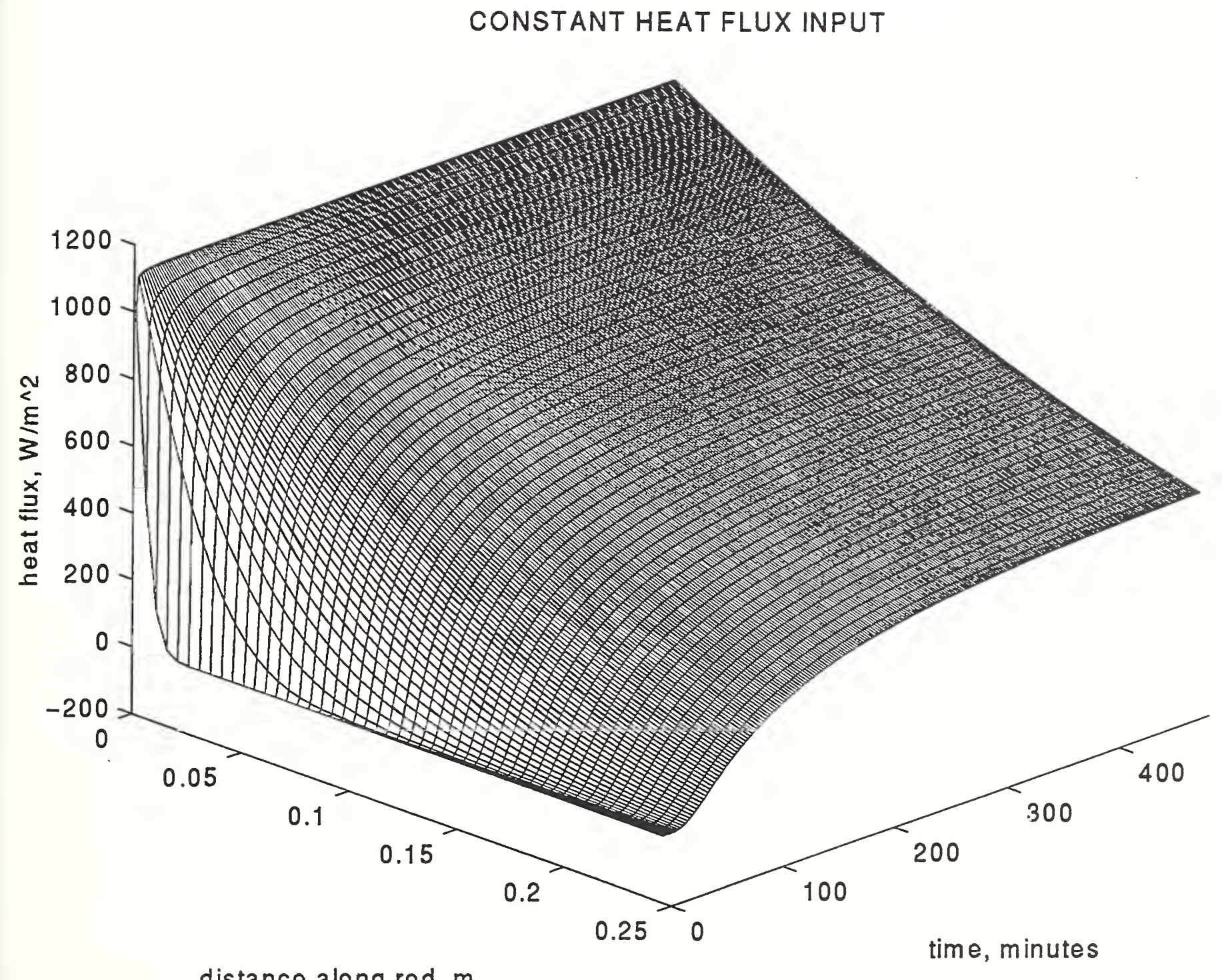

distance along rod, $m$

FIGURE 9 Step Heat Flux Response (Heat Flux Step Amplitude to Yield $20^{\circ} \mathrm{C}$ Asymptotic Temperature Rise) 


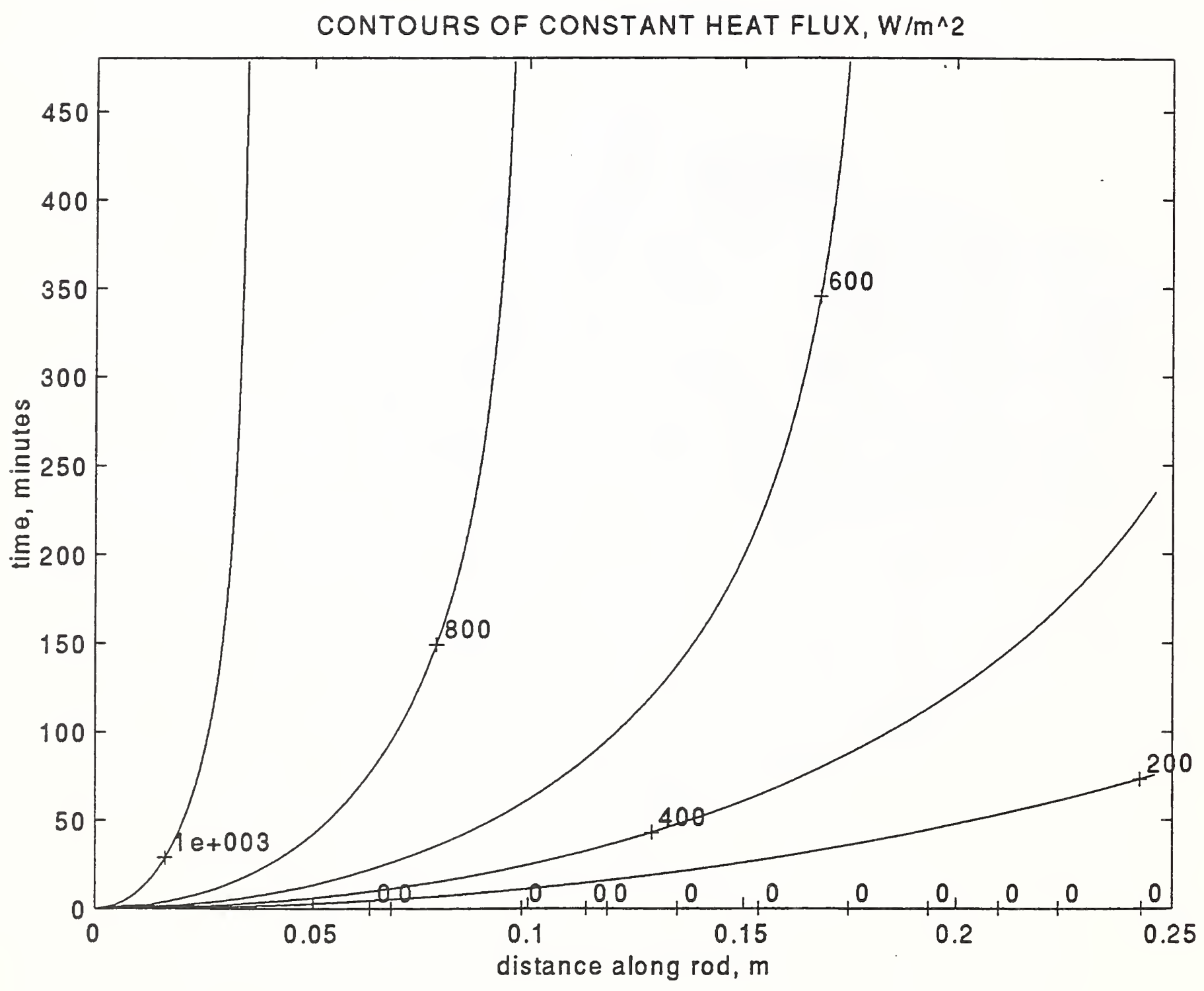

FIGURE 10 Contours of Constant Heat Flux for Step Heat Flux Input 


\section{CONSTANT HEAT FLUX INPUT}

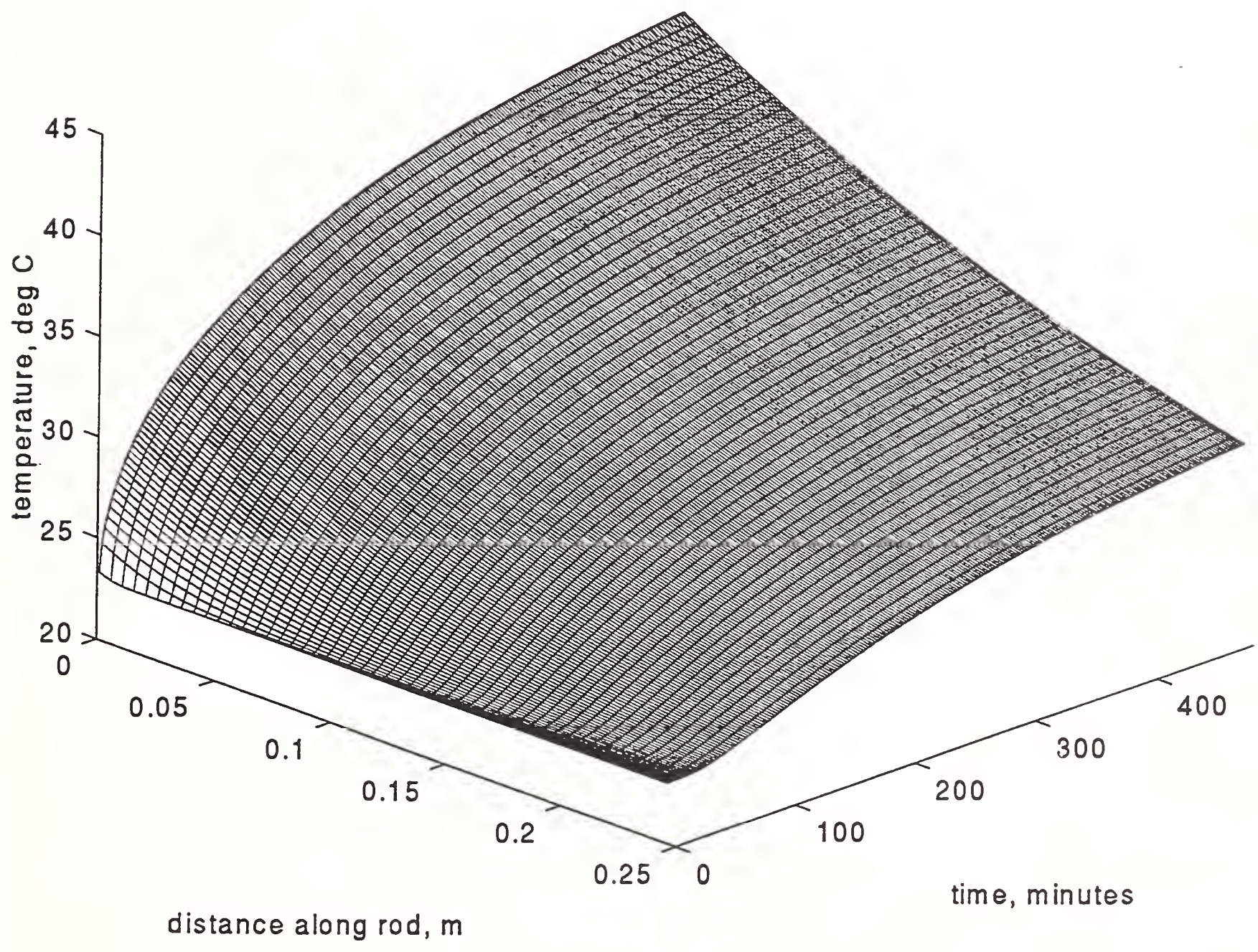

FIGURE 11 Temperature Response to Step Heat Flux Input: Asymptotic $20^{\circ} \mathrm{C}$ Temperature Rise and $23^{\circ} \mathrm{C}$ Ambient Temperature 


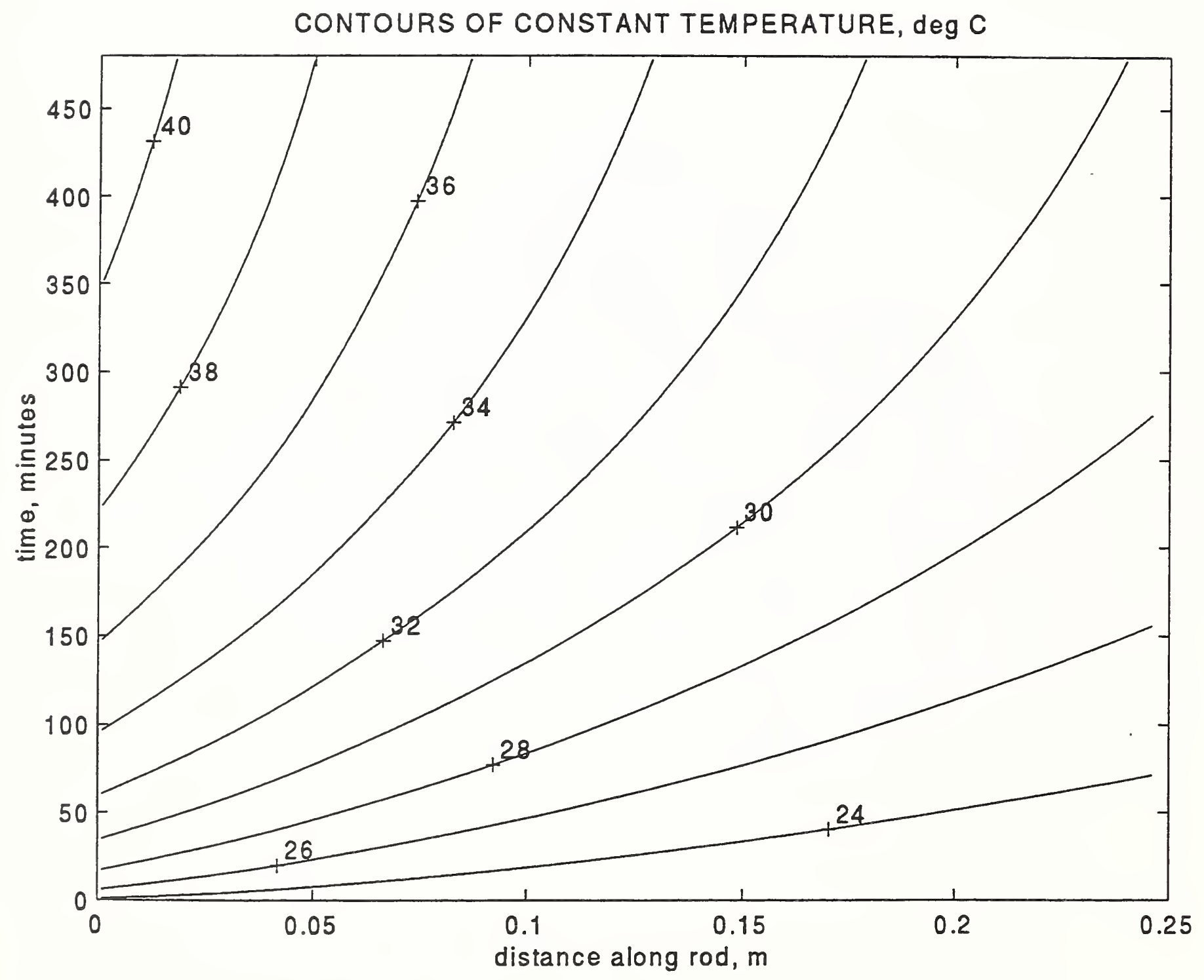

FIGURE 12 Contours of Constant Temperature for a Step Heat Flux Input: Asymptotic $20^{\circ} \mathrm{C}$ Temperature Rise and $23^{\circ} \mathrm{C}$ Ambient Temperature 
CONSTANT HEAT FLUX INPUT

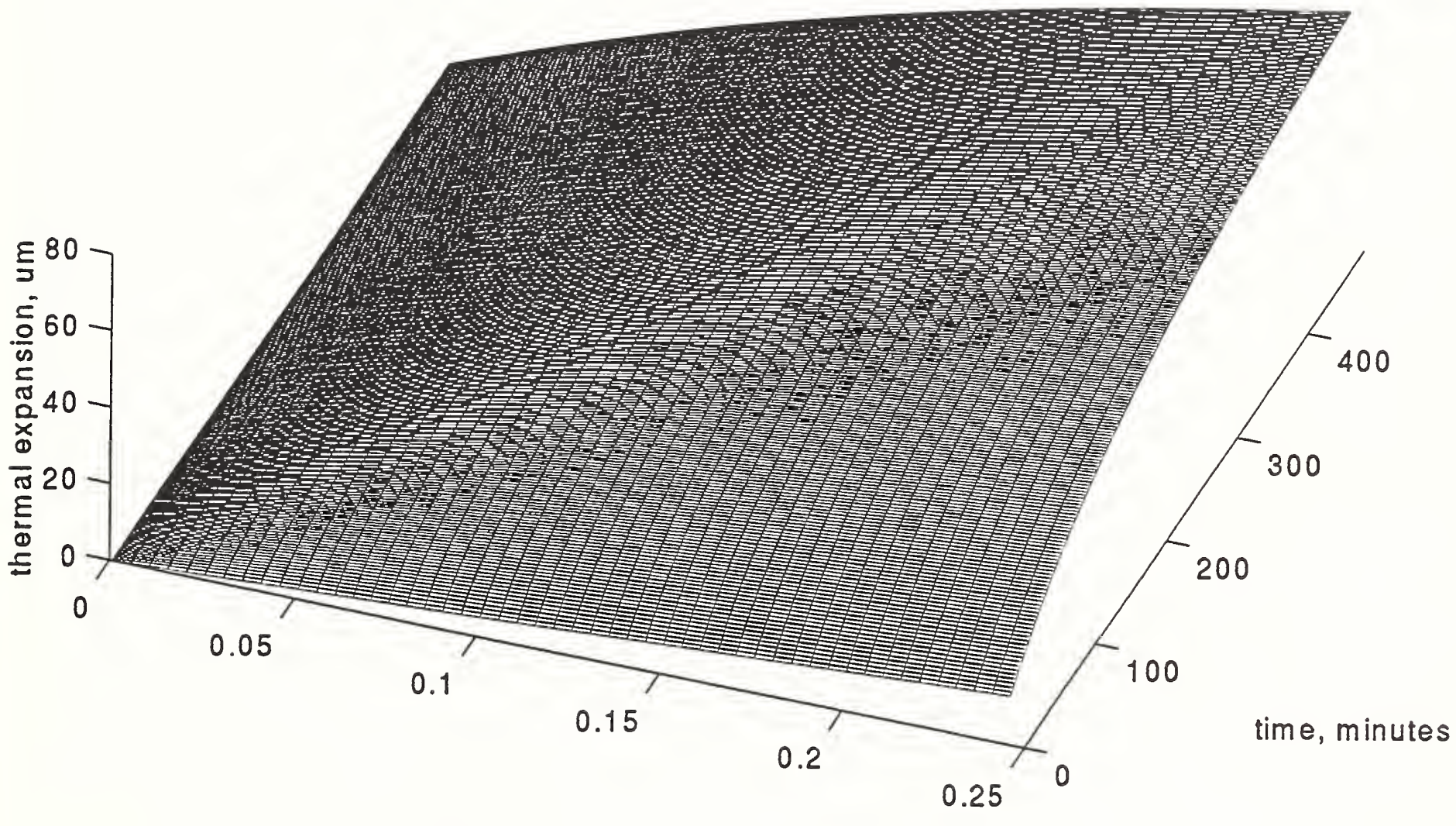

distance along rod, $m$

FIGURE 13 Thermal Expansion for a Step Heat Flux Input:

Asymptotic $20^{\circ} \mathrm{C}$ Temperature Rise, $23^{\circ} \mathrm{C}$ Ambient

Temperature, and $20^{\circ} \mathrm{C}$ Rod Calibration Temperature 
CONTOURS OF CONSTANT THERMAL EXPANSION, UM

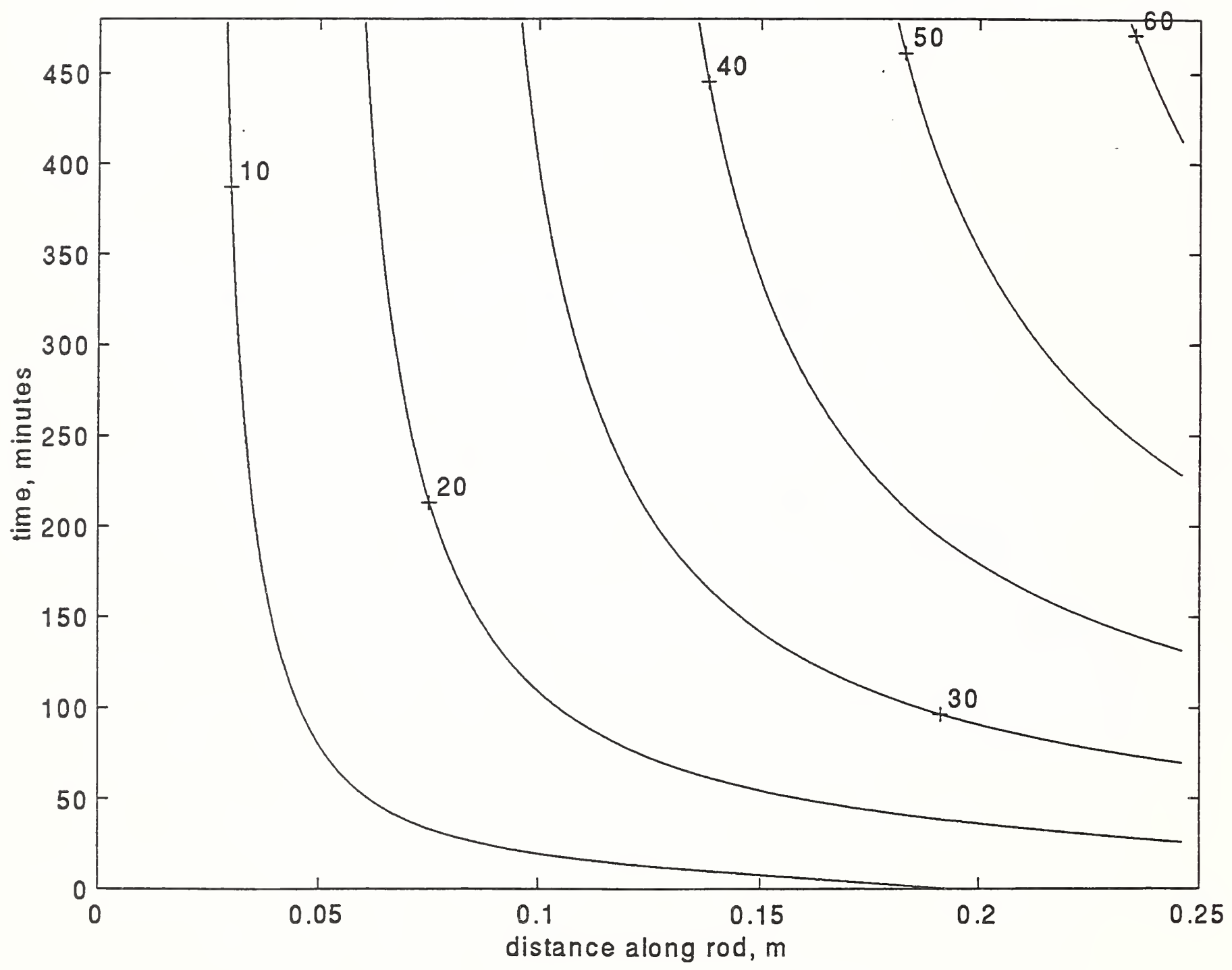

FIGURE 14 Contours of Constant Thermal Expansion for a Step Heat Flux Input: Asymptotic $20^{\circ} \mathrm{C}$ Temperature Rise, $23^{\circ} \mathrm{C}$ Ambient Temperature, and $20^{\circ} \mathrm{C}$ Rod Calibration Temperature 


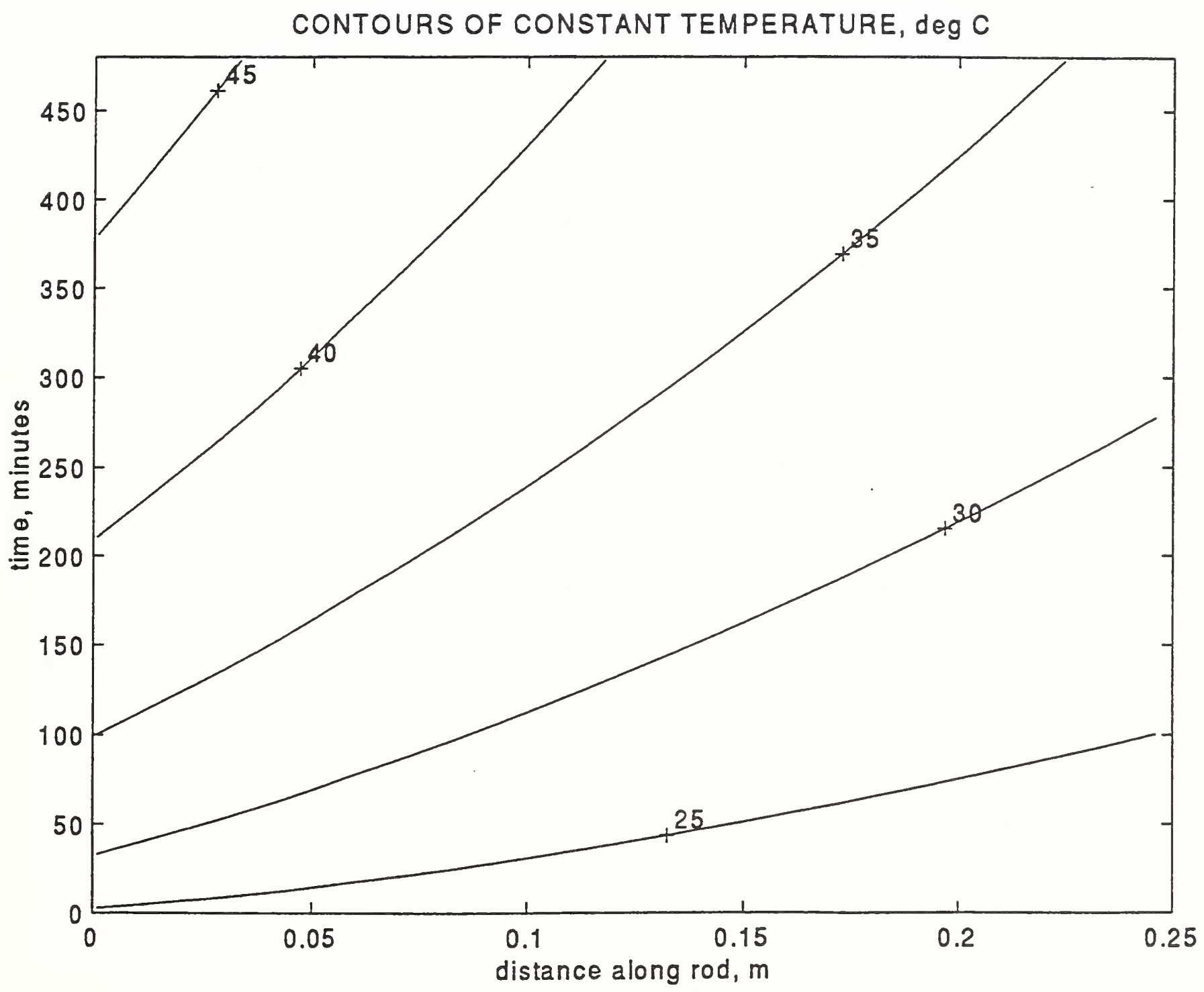

FIGURE 15 Contours of Constant Temperature Response for "Low" Cooling $\left(\lambda=1.2 \cdot 10^{-5} 1 / \mathrm{s}\right)$ Due to a Constant Step Heat Flux Input (Compare to Figures 12 and 17) 


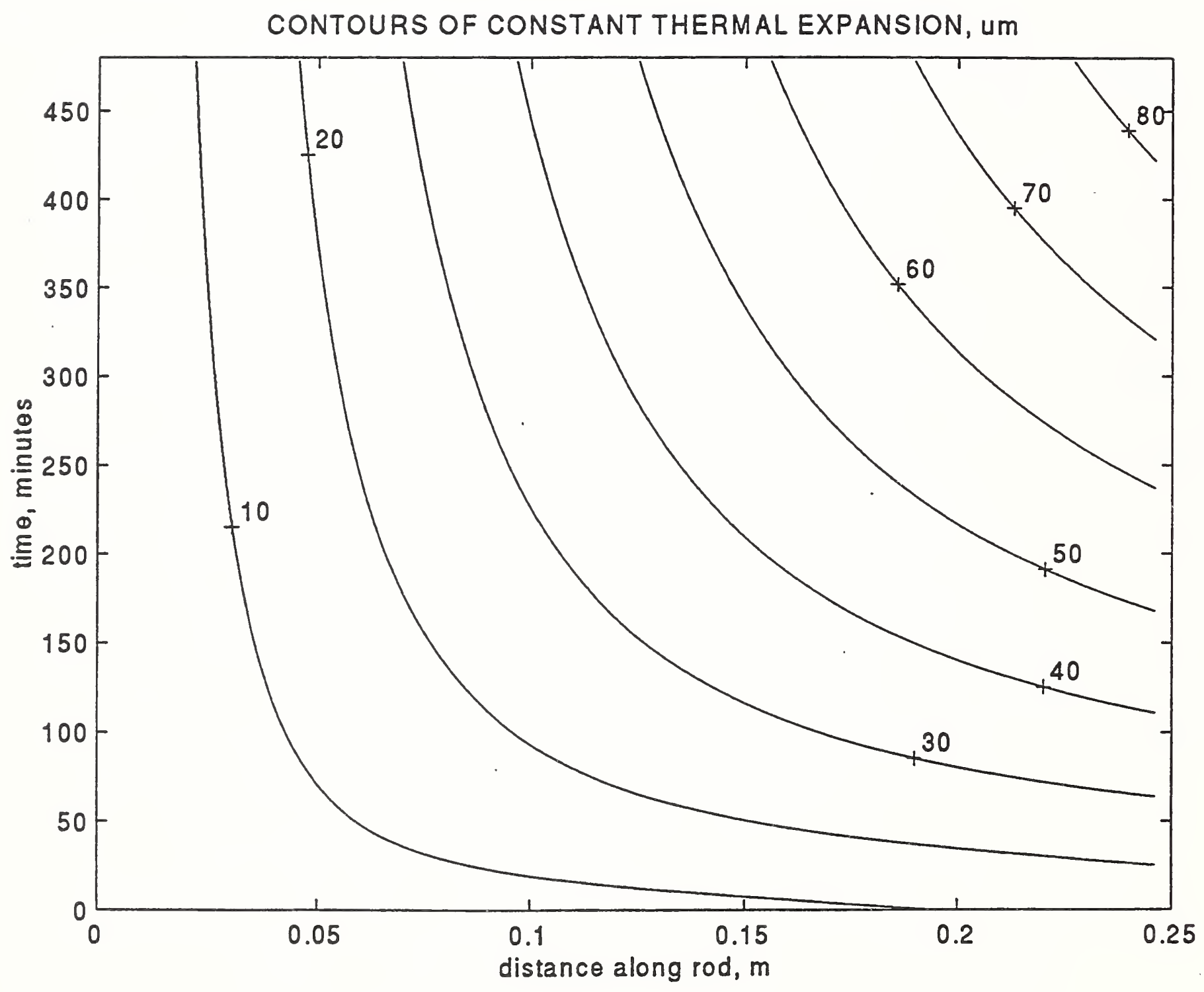

FIGURE 16 Contours of Constant Thermal Expansion Response for "Low" Cooling $\left(\lambda=1.2 \cdot 10^{-5} 1 / \mathrm{s}\right)$ Due to a Constant Step Heat Flux Input (Compare to Figures 14 and 18) 


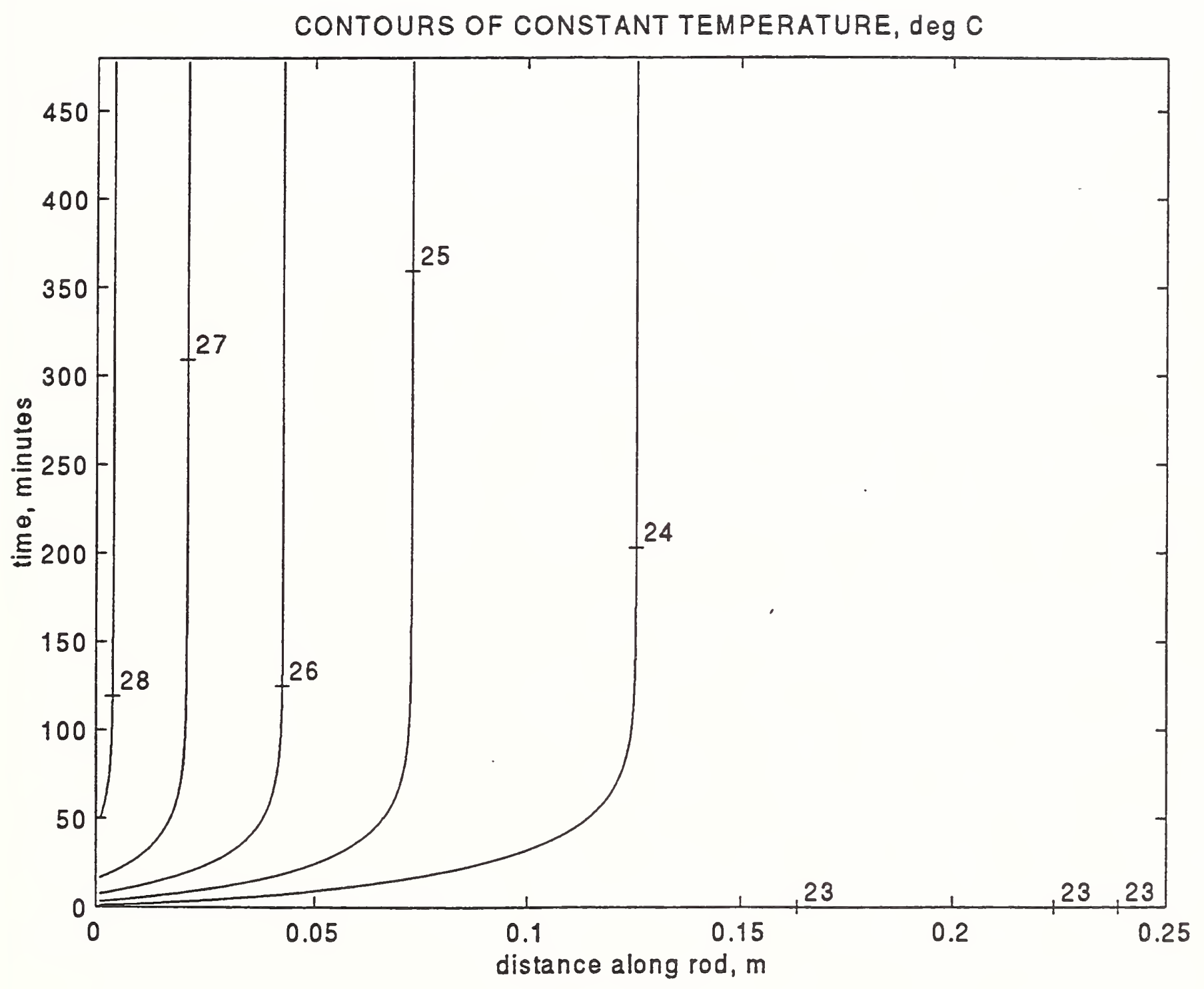

FIGURE 17 Contours of Constant Temperature Response for "High" Cooling $\left(\lambda=7.4 \cdot 10^{-4} 1 / \mathrm{s}\right)$ Due to a Constant Step Heat Flux Input (Compare to Figures 12 and 15) 


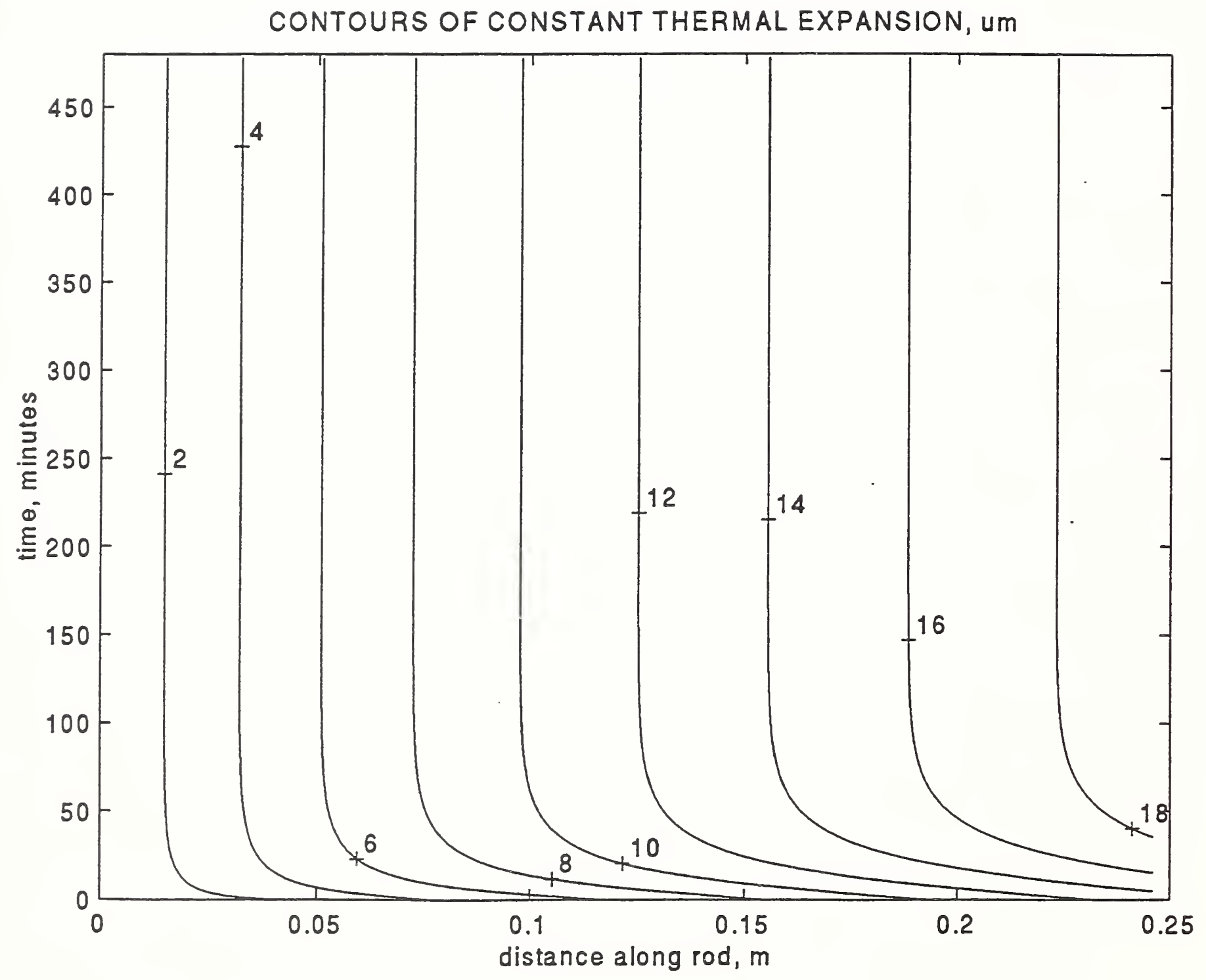

FIGURE 18 Contours of Constant Thermal Expansion Response for "High" Cooling $\left(\lambda=7.4 \cdot 10^{-4} 1 / \mathrm{s}\right)$ Due to a Constant Step Heat Flux Input (Compare to Figures 14 and 16) 


\section{REFERENCES}

1. Falco, J.A. (personal communication) The solid model illustrated is one result of the simulation modeling of the NIST Octahedral Hexapod Machine Tool by The Intelligent Systems Division, Manufacturing Engineering Laboratory, NIST

2. Carslaw, H.S., and Jaeger, J.C.: Conduction of Heat in Solids (2nd Ed), Clarendon Press, Oxford (1986) (Chapter 4, sections 4.1-4.3).

3. Slocum, A.H.: Precision Machine Design, Prentice Hall (1992) (Table 7.3.1, p. 335).

4. Boley, B.A. and Weiner, J.H.: Theory of Thermal Stresses, John Wiley \& Sons, Inc. (1960) (section 7.8(b) pp. 232-234). 



\section{APPENDIX A MATHEMATICAL DETAILS OF HEAT CONDUCTION AND} THERMAL EXPANSION OF A SEMI-INFINITE ROD

This appendix presents an outline of the derivation of the differential equation for heat conduction in a semi-infinite length rod, the solution of this equation for the initial conditions and boundary conditions described below, and the expressions for the stress-free thermal expansion of the rod. The heat conduction problems presented here are completely described in Chapter 4 of Carslaw and Jaeger [A-1]. The expressions for the stress-free thermal expansion of the rod are obtained by integrating the stress-displacement relationship for a rod [A-2]. This approach assumes that the temperature variation of the rod is independent of the strain condition of the rod. That is, the temperature variation is uncoupled from the thermal strain condition.

The notation used in this report for certain parameters is slightly different from the notation used by Carslaw and Jaeger [A-1]. This, however, should not cause any confusion.

\section{A.1 Differential Equation for Heat Conduction}

The problem considered here is a long thin rod exposed to an ambient temperature, $T_{\infty}$, which is assumed constant. The rod has a constant cross-section shape and a varying temperature distribution $T(z, t)$ where $z$ is the distance along the rod and $t$ is time.

Figure A-1 defines the problem being considered. The differential equation is obtained by considering the power balance of the heat flux across the surfaces of an elementary volume of the rod material and the rate of gain of heat within the elementary volume.

The heat flux, $q(z, t)$ per unit cross sectional area, along the length of the rod is proportional to the local spatial gradient of the temperature field. The constant of proportionality is the thermal conductivity of the material, $\mathrm{k}$. The mathematical expression for the the flux is:

$$
q(z, t)=-k \frac{\partial T}{\partial z}
$$

which has physical units of power per unit area.

As indicated in Figure A-1, the net power gain due to the heat flux across the rod cross-section areas is:

$$
+k \frac{\partial^{2} T}{\partial z^{2}} S d z, \quad \text { power gain due to heat conduction along length of rod }
$$




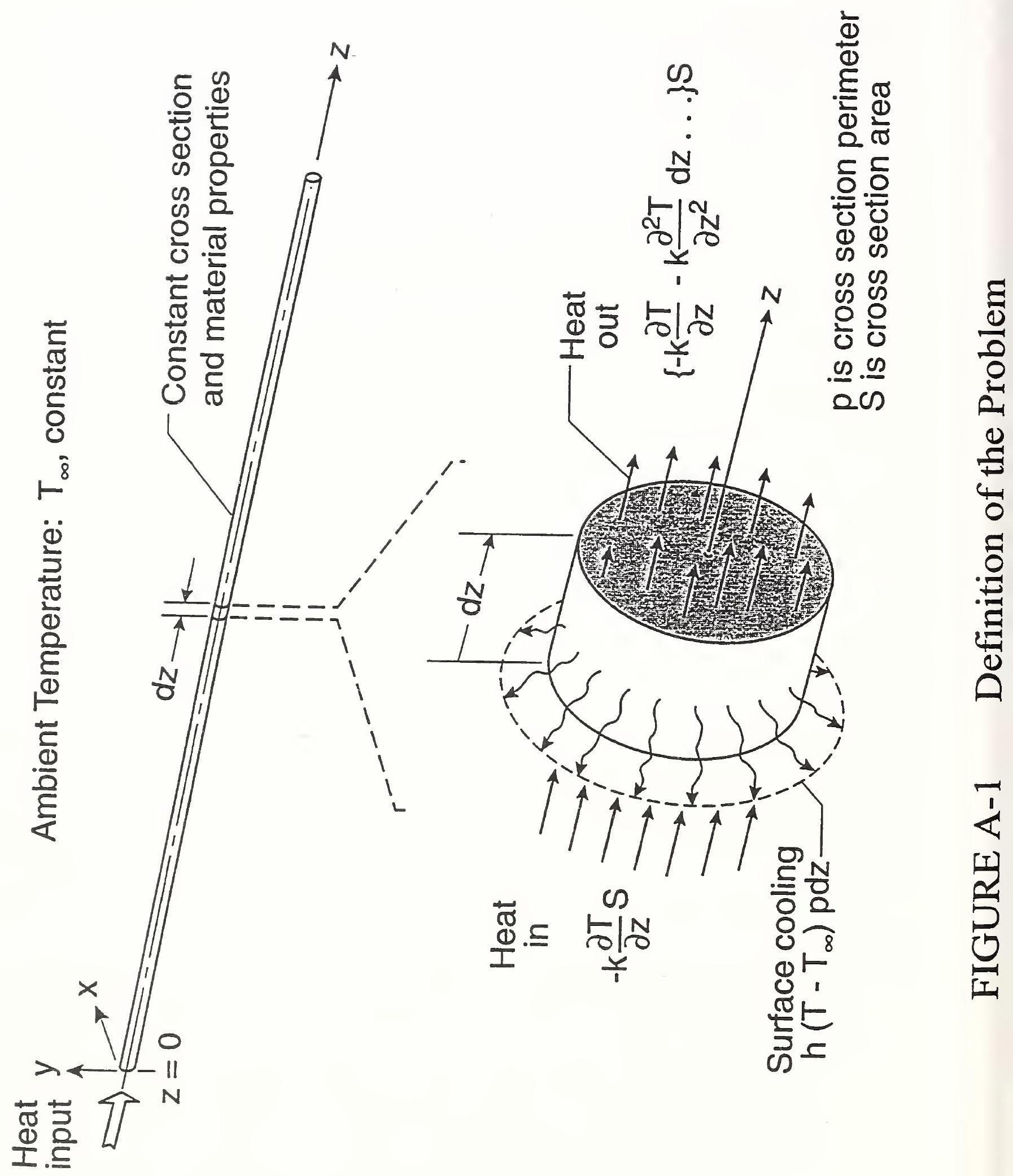


Due to the temperature difference between the surface of the rod and the ambient temperature, heat is lost to the ambient environment at the rate

$$
-h\left(T-T_{\infty}\right) p d z \text {, power lost to environment }
$$

where the surface area is the perimeter of the rod cross-section, $p$, times the length of the element, $\mathrm{dz}$. The parameter $\mathrm{h}$ is discussed in Appendix B.

The rate of gain of power (heat flux) within the element is proportional to the time rate of change of the temperature of the elementary volume of the rod. The rate of gain of power is

$$
\rho c \frac{\partial T}{\partial t} S d z, \quad \text { rate of gain of power within element }
$$

where $\rho$ is the material density of the rod and $\mathrm{c}$ is the specific heat (at constant pressure) of the rod material.

The differential equation is an expression of the equality of power gain plus power lost to the rate of gain of power of the elementary volume. From Eqs. (A-2, -3, -4) one obtains the expression for power balance as:

$$
(k / \rho c) \frac{\partial^{2} T}{\partial z^{2}}-(h p / \rho c S)\left(T-T_{\infty}\right)=\frac{\partial T}{\partial t}
$$

or the differential equation is expressed as:

$$
\kappa \frac{\partial^{2} T}{\partial z^{2}}-\lambda\left(T-T_{\infty}\right)=\frac{\partial T}{\partial t} ; z>0, t>0
$$

where $\kappa=k / \rho c \quad$ thermal diffusivity of the rod material

$\lambda=\mathrm{hp} / \mathrm{\rho cS} \quad$ cooling coefficient

One final simplification of the differential equation is convenient. We change the temperature scale so that

$$
T(z, t)=T^{*}(z, t)+T_{\infty}
$$

Since $T_{\infty}$ is constant, the differential equation is

$$
\kappa \frac{\partial^{2} T^{*}}{\partial z^{2}}-\lambda T^{*}=\frac{\partial T^{*}}{\partial t} ; z>0, t>0
$$


where $T^{*}(z, t)$ is the temperature of the rod relative to the constant ambient temperature, $T_{\infty}$. For no surface cooling, $\lambda=0$ and equation (A-7) reduces to the one dimension heat conduction equation.

\section{A.2 Initial Condition and Boundary Condition}

For a solution to equation (A-7) one must specify an initial condition and a boundary condition on the function $T^{*}$.

The initial condition specifies the value of $T^{*}$ at time, $t=0$ (really it is limit $T^{*}(z, t)$ ).

$$
\mathrm{t} \rightarrow \mathrm{O}^{+}
$$

The boundary condition specifies the value of $\mathrm{T}^{*}$ at the surfaces of the rod. For the present problem, the only surface of the semi-inifinite rod for which one can specify the temperature $T^{*}$ is the rod cross-section at $z=0$ (really it is limit $T^{*}(z, t)$ ).

$$
\mathrm{z} \rightarrow 0^{+}
$$

Carslaw and Jaeger [A-1] is a very complete compilation of solutions of heat conduction problems. It is a very safe bet to say that if a problem has an analytical solution, the problem is presented in Carslaw and Jaeger. The solutions discussed below are presented in Carslaw and Jaeger (Chapter IV, pp. 133-136).

For the problem discussed in the report, the initial temperature condition of the rod is:

$$
\begin{aligned}
& \operatorname{limit}_{t \rightarrow 0^{+}} T(z, t)=T_{\infty} \text {, a constant; } z>0 \\
& \text { or } \\
& \operatorname{limit}_{z \rightarrow 0^{+}} T^{*}(z, t)=0 ; \quad z>0
\end{aligned}
$$

That is, the rod is placed in the environment at $T_{\infty}$ and reaches temperature equilibrium.

The boundary condition for the problem discussed in the report is a constant temperature at the rod cross-section $z=0$. That is, a heat source is brought into contact with the rod at $z=0$ and maintains the temperature for all time $t>0$. The mathematical expression for this condition is

$$
\underset{z \rightarrow 0^{+}}{\operatorname{limit}} T(z, t)=T_{0}, \text { a constant; } z>0
$$


or

$\operatorname{limit} \mathrm{T}^{*}(\mathrm{z}, \mathrm{t})=\mathrm{T}_{0}-\mathrm{T}_{\infty}=\mathrm{T}^{*},{ }_{0}$, a constant, $\mathrm{t}>0$ $z \rightarrow 0^{+}$

A.3 Semi-Infinite Rod, Initial Temperature Zero, Surface $z=0$ Maintained at Constant Temperature for $t>0$

The mathematical statement of this problem is:

$$
\kappa \frac{\partial^{2} T^{*}}{\partial z^{2}}-\lambda T^{*}=\frac{\partial T^{*}}{\partial t}
$$

initial condition: $\quad \operatorname{limit}_{\mathrm{t} \rightarrow 0^{+}} \mathrm{T}^{*}(\mathrm{z}, \mathrm{t})=0 ; \mathrm{z}>0$

boundary condition: limit $\mathrm{T}^{*}(\mathrm{z}, \mathrm{t})=\mathrm{T}^{*}{ }_{\mathrm{o}} ; \mathrm{t}>0$

$$
\mathrm{z} \rightarrow 0^{+}
$$

The solution of this problem is given in Carslaw and Jaeger, Chapter IV, Eq. (4.2(7)) page 135. The result is

$$
\begin{aligned}
T^{*}(z, \mathrm{t}) & =\mathrm{T}^{*}{ }_{\mathrm{o}} \Phi(\mathrm{z}, \mathrm{t}) \\
\Phi(z, t) & =\cosh (z \sqrt{\lambda / \kappa})-1 / 2 e^{z \sqrt{\lambda / \kappa}} \cdot \operatorname{erf}(z / 2 \sqrt{\kappa t}+\sqrt{\lambda t}) \\
& -1 / 2 e^{-z \sqrt{\lambda / \kappa}} \cdot \operatorname{erf}(z / 2 \sqrt{\kappa t}-\sqrt{\lambda t})
\end{aligned}
$$

where $\operatorname{erf}(\zeta) \equiv \frac{2}{\sqrt{\pi}} \int_{0}^{\zeta} e^{-\eta^{2}} d \eta$ is the error function $\operatorname{erfc}(\zeta)=1-\operatorname{erf}(\zeta)$ is the complementary error function.

The error function is obviously related to the exponential function. It is useful to state some specific values and relationships for the error function:

$$
\begin{aligned}
& \operatorname{erf}(0)=0 \\
& \operatorname{erf}(\infty)=1 \\
& \operatorname{erf}(-\zeta)=-\operatorname{erf}(\zeta)
\end{aligned}
$$


If the reader is interested, a comprehensive description of the error function is given in Chapter 7 of the NBS Handbook of Mathematical Functions [A-3].

Limiting values for the function $\Phi(\mathrm{z}, \mathrm{t})$ given in $\mathrm{Eq}(\mathrm{A}-11 \mathrm{~b})$ are:

\begin{tabular}{|c|c|c|}
\hline $\operatorname{limit}_{z \rightarrow 0^{+}} \Phi(z, t)=1$ & or & $\operatorname{limit}_{z \rightarrow 0^{+}} T^{*}(z, t)=T^{*}$ \\
\hline $\operatorname{limit}_{z \rightarrow \infty} \Phi(z, t)=0$ & or & $\operatorname{limit}_{z \rightarrow \infty} T^{*}(z, t)=0$ \\
\hline $\operatorname{limit}_{t \rightarrow 0^{+}} \Phi(z, t)=0$ & or & $\operatorname{limit}_{t \rightarrow 0^{+}} T^{*}(z, t)=0$ \\
\hline $\operatorname{limit}_{t \rightarrow \infty} \Phi(z, t)=e^{-z V}(\lambda / k)$ & or & $\operatorname{limit}_{\mathrm{t} \rightarrow \infty} \mathrm{T}^{*}(\mathrm{z}, \mathrm{t})=\mathrm{T}^{*}{ }_{0} \mathrm{e}^{-\mathrm{z} \sqrt{2}(\lambda / \mathrm{k})}$ \\
\hline
\end{tabular}

The last limit condition is the steady or time-independent temperature distribution of the rod.

A.4 Semi-Infinite Rod, Initial Heat Flux Zero, Surface $\mathrm{z}=0$ Maintained at Constant Heat Flux for $\mathrm{t}>0$

Mathematically, this problem is identical to the problem described in A.3 above -- only the nomenclature is changed. The relation between the heat flux and temperature is given by $\mathrm{Eq}(\mathrm{A}$ 1). Clearly, the heat flux, $q(z, t)$, must satisfy the same differential equation as the temperature. The initial condition and the boundary condition for $q(z, t)$ are identical to the temperature conditions described in Section A.3. Hence, the expression for the heat flux in the semi-infinite rod is

$$
\mathrm{q}(\mathrm{z}, \mathrm{t})=\mathrm{q}_{\mathrm{o}} \Phi(\mathrm{z}, \mathrm{t})
$$

where $\Phi(z, t)$ is given by $\mathrm{Eq}(\mathrm{A}-11 \mathrm{~b})$.

Now, one obtains the expression for the temperature $T^{*}(z, t)$ by a direct integration of $\operatorname{Eq}(\mathrm{A}-1)$. The formal expression is

$$
\int_{z}^{\infty} \frac{\partial T *}{\partial \eta} d \eta=\left.T *(\eta, t)\right|_{z} ^{\infty}=-1 / k \int_{z}^{\infty} q(\eta, t) d \eta
$$

or

$$
T *(z, t)=\left(q_{0} / k\right) \int_{z}^{\infty} \Phi(\eta, t) d \eta
$$


since limit $T^{*}(z, t)=0$ on the physical basis that the rod is so long the locations very distant from $z \rightarrow \infty$ $z=0$ never experience a temperature change (i.e., all the heat is dissipated due to the cooling of the rod).

The integral appearing in $\mathrm{Eq}(\mathrm{A}-13 \mathrm{~b})$ can be directly obtained in analytical form. The result is:

$$
\begin{aligned}
T^{*}(z, t)= & -\sqrt{\kappa / \lambda}\left(q_{o} / k\right)\{\sinh (z \sqrt{\lambda / \kappa}) \\
& -1 / 2 e^{z \sqrt{\lambda / \kappa} \cdot} \cdot \operatorname{erf}(z / 2 \sqrt{\kappa t}+\sqrt{\lambda t}) \\
& \left.+1 / 2 e^{-z \sqrt{\lambda \kappa} \cdot} \cdot \operatorname{erf}(z / 2 \sqrt{\kappa t}-\sqrt{\lambda t})\right\} .
\end{aligned}
$$

Limiting values for the temperature $T^{*}(z, t)$ are

$$
\begin{aligned}
& \operatorname{limit}_{z \rightarrow 0^{+}} T^{*}(z, t)=\sqrt{(\kappa / \lambda)}\left(q_{0} / k\right) \operatorname{erf}(\sqrt{(\lambda t))} \\
& \operatorname{limit}_{z \rightarrow \infty} T^{*}(z, t)=0 \\
& \operatorname{limit}_{t \rightarrow 0^{+}} T^{*}(z, t)=0 \\
& \operatorname{limit}_{t \rightarrow \infty} T^{*}(z, t)=\sqrt{(k / \lambda)\left(q_{0} / k\right) e^{-z \sqrt{ }(\lambda / k)}}
\end{aligned}
$$

The first limit above is the time variation of the temperature at $z=0$ due to the application of the constant heat flux, $q_{0}$, at $z=0$. For large times following initiation of the heating, the

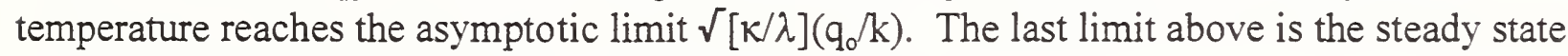
(i.e. time independent) temperature distribution of the rod.

The reader should compare the temperature expressions given in Eqs(A-11) and Eqs(A-14). The detail expressions are different -- which is to be expected. However, the limiting values of the temperature expressions for a large time are functionally identical. Physically, this means that for large time after initiating the heating, the temperature distribution along the rod has the same functional form for both heating conditions considered here. Knowledge of the steady-state temperature distribution does not indicate the nature of the heat source.

\section{A.5 Stress-Free Thermal Expansion}




\section{A.5.1 Basic Considerations}

The temperature variation along the length of the rod causes a thermal expansion of the rod. Since the rod is long and slender, the thermal expansion is one dimensional in the direction of the rod axis. Further, it is assumed that the rod expansion is unconstrained so that no elastic stress is induced in the rod.

Using the stress-strain relations for the rod material and the strain-displacement relation considering a temperature change of $\mathrm{T}(\mathrm{z}, \mathrm{t})$, the thermal expansion, $\mathrm{w}(\mathrm{z}, \mathrm{t})$, is related to the temperature change as:

$$
\frac{\partial w}{\partial z}=\alpha T(z, t)
$$

where $\alpha$ is the coefficient of thermal expansion of the rod material (assumed constant).

Formally integrating this expression, one obtains

$$
w(z, t)=w(0, t)+\alpha \int_{0}^{z} T(\zeta, t) d \zeta
$$

where $w(0, t)$ is the thermal expansion of the rod at $z=0$.

We are interested in the thermal expansion of the rod relative to the plane $z=0$. Hence, $w(0, t)=$ 0 . Then, to compute the thermal expansion one must integrate the expression for the temperature distribution with respect to the distance along the rod. However, it is first necessary to define a constant reference temperature for which one defines the state of zero thermal expansion. That is, the temperature change of the rod is measured relative to a defined reference temperature.

Denoting the reference temperature as $T_{\text {cal }}$ and using the temperature scale given by $\mathrm{Eq}(\mathrm{A}-6)$, the expression for the temperature is:

$$
T(z, t)=T_{\infty}-T_{\text {cal }}+T^{*}(z, t)
$$

and the expression for the thermal expansion is

$$
w(z, t)=\alpha\left(T_{\infty}-T_{c a l}\right) z+\alpha \int_{0}^{z} T^{*}(\eta, t) d \eta .
$$

The explicit expression for $T^{*}(z, t)$ depends upon the solution of the temperature problem defined by $\mathrm{Eq}(\mathrm{A}-10)$. For a constant temperature input, the expression for $\mathrm{T}^{*}(\mathrm{z}, \mathrm{t})$ is given by $\operatorname{Eq}(\mathrm{A}-11)$. For a constant heat flux input, the expression for $T^{*}(z, t)$ is given by $\mathrm{Eq}(\mathrm{A}-14)$. Although these 
expressions for $T^{*}(z, t)$ look complicated, they can be integrated to give an explicit functional expression for the thermal expansion. These expressions are presented below. First, however, a brief discussion of the above expression for thermal expansion, Eq(A-16b), is worthwhile.

First, consider that the rod is manufactured with a scale along its length. This scale may be a ruling as for a common ruler or it may be a lead screw. Assume that the rod is manufactured and the ruling calibrated at a constant temperature, $T_{\text {cal }}$. (This is the reason for the nomenclature $T_{\text {cal }}$ for the reference temperature.) Now, assume that the rod is placed in an environment at a temperature $T_{\infty}$ and the rod experiences a temperature change until the rod is at the steady temperature $T_{\infty}$. This temperature change, $T_{\infty}-T_{\text {cal }}$, results in a thermal expansion of the rod which is given by the first term in $\mathrm{Eq}(\mathrm{A}-16 \mathrm{~b})$. This thermal expansion is relative to the plane $z=0$ of the rod. The thermal expansion results in a scale error that is directly proportional to the temperature change and the calibrated distance, $z$, from the end of the rod. At the uniform temperature, $T_{\infty}$, the measured distance using the manufactured ruling is:

$$
\mathrm{z}_{\text {measured }}=\mathrm{z}+\mathrm{w}(\mathrm{z}, 0) @ \mathrm{~T}_{\infty}
$$

After the initiation of the heating of the rod at $z=0$, the measured distance using the manufactured ruling is:

$$
\mathrm{z}_{\text {measured }}=\mathrm{z}+\mathrm{w}(\mathrm{z}, \mathrm{t}) \text {. }
$$

Now, expressions for the thermal expansion of the rod are obtained.

\section{A.5.2 Thermal Expansion for Constant Temperature Input}

For a constant temperature input, the temperature response $T^{*}(z, t)$ is given by $\mathrm{Eq}(\mathrm{A}-11)$. Substituting this expression into $\mathrm{Eq}(\mathrm{A}-16 \mathrm{~b})$ and integrating, one obtains the result

$$
\begin{aligned}
w(z, t)=\alpha\left(T_{\infty}-T_{c a l}\right) & z+\alpha \sqrt{\kappa / \lambda}\left(T_{0}-T_{\infty}\right)\{\sinh (z \sqrt{\lambda / \kappa})+\operatorname{erf}(\sqrt{\lambda t}) \\
& -1 / 2 e^{z \sqrt{\lambda / \kappa}} \operatorname{erf}(z / 2 \sqrt{\kappa t}+\sqrt{\lambda t}) \\
& \left.+1 / 2 e^{-z \sqrt{\lambda / \kappa}} \operatorname{erf}(z / 2 \sqrt{\kappa t}-\sqrt{\lambda t})\right\}
\end{aligned}
$$

where $T_{0}$ is the initial temperature input to the rod at $z=0$ (see $E q(A-9)$ ).

The limiting values for the expression for thermal expansion are:

$$
\begin{aligned}
& \operatorname{limit}_{z \rightarrow 0^{+}} w(z, t)=0 \\
& \left.\operatorname{limit}_{z \rightarrow \infty} w(z, t)=\alpha\left(T_{\infty}-T_{\text {cal }}\right) z_{\text {large }}+\alpha \sqrt{(\kappa / \lambda} / \lambda\right)\left(T_{0}-T_{\infty}\right) \operatorname{erf} \sqrt{ }(\lambda t)
\end{aligned}
$$


Note: $z_{\text {large }}$ is a large value of $z$ and not infinite

$$
\begin{aligned}
& \operatorname{limit}_{t \rightarrow 0^{+}} w(z, t)=\alpha\left(T_{\infty}-T_{\text {cal }}\right) z \\
& \operatorname{limit}_{t \rightarrow \infty} w(z, t)=\alpha\left(T_{\infty}-T_{\text {cal }}\right) z+\alpha \sqrt{ }(\kappa / \lambda)\left(T_{0}-T_{\infty}\right)\left[1-e^{-2 \sqrt{ }(\lambda / k)}\right]
\end{aligned}
$$

The first limit emphasizes that the thermal expansion is zero at the $z=0$ cross-section of the rod. The second limit gives the time dependence of the thermal expansion for large $z$. The third limit is the initial thermal expansion due to the temperature difference between the calibration temperature and the ambient temperature. The last limit is the steady state (i.e., time independent) thermal expansion.

\section{A.5.3 Thermal Expansion for Constant Heat Flux Input}

For a constant heat flux input, the temperature response $T^{*}(z, t)$ is given by $\mathrm{Eq}(\mathrm{A}-14)$. Substituting this expression into $\mathrm{Eq}(\mathrm{A}-16 \mathrm{~b})$ and integrating, one obtains the result

$$
\begin{aligned}
w(z, t)=\alpha\left(T_{\infty}-T_{c a l}\right) & +\alpha(\kappa / \lambda)\left(q_{0} / k\right)\{1-\cosh (z \sqrt{\lambda / \kappa}) \\
& -e^{-\lambda t} \operatorname{erf}(z / 2 \sqrt{\kappa t}) \\
& +1 / 2 e^{z \sqrt{\lambda / \kappa}} \operatorname{erf}(z / 2 \sqrt{\kappa t}+\sqrt{\lambda t}) \\
& \left.+1 / 2 e^{-z \sqrt{\lambda / \kappa}} \operatorname{erf}(z / 2 \sqrt{\kappa t}-\sqrt{\lambda t})\right\}
\end{aligned}
$$

where $q_{o}$ is the initial heat flux input to the rod at $z=0$ (see $E q(A-12)$ ).

The limiting values for the expression for thermal expansion are:

$$
\begin{aligned}
& \operatorname{limit}_{\mathrm{z} \rightarrow 0^{+}} w(z, t)=0 \\
& \operatorname{limit}_{\mathrm{z} \rightarrow \infty} w(z, t)=\alpha\left(T_{\infty}-T_{\text {cal }}\right) z_{\text {large }}+\alpha \sqrt{ }(\kappa / \lambda)\left(q_{0} / k\right)\left[1-e^{-\lambda t}\right] \\
& \quad \text { Note: } z_{\text {large }} \text { is a large value of } z \text { and not infinite } \\
& \operatorname{limit}_{t \rightarrow 0^{+}} w(z, t)=\alpha\left(T_{\infty}-T_{\text {cal }}\right) z \\
& \operatorname{limit}_{t \rightarrow \infty} w(z, t)=\alpha\left(T_{\infty}-T_{\text {cal }}\right) z+\alpha \sqrt{ }(\kappa / \lambda)\left(q_{0} / k\right)\left[1-e^{-z V(\lambda / k)}\right]
\end{aligned}
$$


The first limit emphasizes that the thermal expansion is zero at the $\mathrm{z}=0$ cross-section of the rod. The second limit gives the time dependence of the thermal expansion for large $z$. The third limit is the initial thermal expansion due to the temperature difference between the calibration temperature and the ambient temperature. The last limit is the steady state (i.e. time independent) thermal expansion. The reader should note that the steady state thermal expansion for constant heat flux, $\mathrm{Eq}(\mathrm{A}-21 \mathrm{~d})$, is functionally identical to the steady state thermal expansion for constant temperature input, $\mathrm{Eq}(\mathrm{A}-19 \mathrm{~d})$.

Appendix A - REFERENCES

[A-1] Carslaw, H.S. and Jaeger, J.C.: Heat Conduction in Solids (2nd Ed.), Clarendon Press, Oxford (1986)

[A-2] Boley, B.A. and Weiner, J.H.: Theory of Thermal Stresses, John Wiley \& Sons Inc (1960) (Chapter 8, pp 243-271)

[A-3] Abramowitz, M. and Stegun, I.L. (Ed): Handbook of Mathematical Functions with Formulas, Graphs, and Mathematical Tables, U.S. Department of Commerce, National Bureau of Standards Applied Mathematics Series 55 (10th Printing, Dec. 1972) (Chapter 7 pp 297-304) 



\section{APPENDIX B - SURFACE COOLING DETAILS}

As described in Appendix A, surface cooling along the length of the rod is described by the term $\lambda\left(T-T_{\infty}\right)$ in Eq $(A-5 b)$. The parameter $\lambda$ defines the cooling rate and is expressed in terms of the physical parameters as

$$
\lambda \equiv \mathrm{hp} / \mathrm{\rho cS}
$$

where $h \quad$ is the convection heat transfer coefficient between the lateral surface of the rod and the ambient environment

$\mathrm{p} \quad$ is the perimeter of the rod cross-section

$\mathrm{S} \quad$ is the area of the rod cross-section

$\rho \quad$ is the mass density of the rod material

c is the specific heat (at constant pressure) of the rod material.

The discussion in this appendix focuses upon the estimation of the heat transfer coefficient, $h$. This estimation is rather "cookbook" for persons familiar with heat transfer problems. An outline of the procedure is given so that the reader may appreciate the detail considerations without the pain of a refresher course in heat transfer. For more detail, the interested reader may consult reference $[\mathrm{B}-1]$.

\section{B.1 Estimation of the Convection Heat Transfer Coefficient, $h$}

For practical problems, we consider the rod to be placed in air at a represenstative room temperature of $23^{\circ} \mathrm{C}\left(296.2^{\circ} \mathrm{K}\right)$ and atmospheric pressure. The properties of air are extensively tabulated [B-1, Table A-5, p.661].

First, it is necessary to calculate the "film" temperature of the rod surface-air interface. The film temperature is defined as

$$
\mathrm{T}_{\mathrm{f}}(\mathrm{z}, \mathrm{t})=\left(\mathrm{T}(\mathrm{z}, \mathrm{t})+\mathrm{T}_{\infty}\right) / 2,{ }^{\circ} \mathrm{K}
$$

using the notation of Appendix A on the right hand side and a subscript $f$ to denote "film".

The film temperature, $\mathrm{T}_{\mathrm{f}}$, is used to look up the properties of air that are needed to estimate the heat transfer coefficient, h. From equation (B-2) we see that the film temperature is a function of both position along the rod and time. Strictly speaking, the heat transfer coefficient also is a function of position and time. Such considerations lead to non-linear problems in heat conduction. In Appendix $\mathrm{A}$, it was assumed that the parameters $\mathrm{h}$ and $\lambda$ were constants so that the resulting differential equation $(\mathrm{Eq}(\mathrm{A}-7))$ is linear. For the present development we make the simplifying assumption that $T_{f}=T_{\infty}$ which is the initial temperature condition for the developments in Appendix A. 
The cooling law expressed by Eq(A-3) corresponds to forced convection cooling in the heat transfer world. The heat transfer coefficient is determined empirically and depends upon the cross-section shape and the orientation of the transverse air velocity relative to the cross-section.

Since ball screws are of circular cross-section, the following discussion is limited to this shape (i.e., our rod is a long circular cylinder).

Knowing the film temperature $\left(T_{f} \approx T_{\infty}\right)$ and the cross-section shape, one is then in a position to compute the heat transfer coefficient. For a circular cross-section cooled by a transverse low velocity air flow the Nusselt number is empirically related to the Reynolds number and the Prandtl number where the properties of air are evaluated at the film temperature (see Reference B-1, Chapter 6). The Nusselt, Reynolds and Prandtl numbers are dimensionless numbers comprising groupings of the physical properties of the fluid surrounding the rod and a length parameter taken as the rod diameter.

For the present problem (or notation) we have:

$\begin{array}{ll}\text { Nusselt number: } & \mathrm{Nu}=\mathrm{hd} / \mathrm{k}_{\mathrm{f}} \\ \text { Reynolds number: } & \mathrm{Re}=\mathrm{du}_{\alpha} / \mathrm{v}_{\mathrm{f}} \\ \text { Prandtl number: } & \operatorname{Pr}=\left(\rho \mathrm{c}_{\mathrm{p}} \mathrm{v} / \mathrm{k}\right)_{\mathrm{f}}\end{array}$

where $d$ is the diameter of the circular cross-section rod

$\mathrm{k}$ is the thermal conductivity of air

$u_{\infty}$ is the transverse velocity of the air

$\rho$ is the density of air

$c_{p}$ is the specific heat of air at constant pressure

$v$ is the kinematic viscosity of air

subscript $f$ denotes the quantity evaluated at atmospheric pressure and $T_{f} \approx T_{\infty}$

First, one must calculate the Reynolds number based on the rod diameter. For the present discussion, we consider a range of rod diameters, cross-flow air velocity, and air temperature. These ranges are given in Table B-1. For these ranges, the range of Reynolds number is:

$$
190<\operatorname{Re}<13300
$$

and the range of Pandtl number is:

$$
0.689<\operatorname{Pr}<0.722
$$

Knowing the Reynolds number and the Prandtl number, one uses an empirical relationship between $\operatorname{Re}$ and Pr to estimate the Nusselt number for the rod-air state. Several such relationships are available and are usually restricted to a specific range of Reynolds number. For 
example, see reference [B-1] Equation (6-18). For the range of parameters described above, the range of Nusselt number is:

$$
8<\mathrm{Nu}<71 .
$$

The importance of the Nusselt number is that the heat transfer coefficient, $h$, and the cooling coefficient, $\lambda$, are directly proportional to the Nusselt number.

Knowing the Nusselt number, one immediately calculates the heat transfer coefficient, h. The range is:

$$
1.8<\mathrm{h}<31.6, \quad \mathrm{~W} / \mathrm{m}^{2}{ }^{\circ} \mathrm{C} .
$$

To calculate the cooling coefficient, $\lambda$, one must specify the rod material in addition to the parameters discussed above. As presented in Table B-1, for steel rods the range of cooling coefficients is [B-2]:

$$
1.2 \cdot 10^{-5}<\lambda<7.2 \cdot 10^{-4}, \quad 1 / \mathrm{s} \text {. }
$$

For air at $\mathrm{T}_{\infty}=300^{\circ} \mathrm{K}=26.85^{\circ} \mathrm{C}$ the range of $\mathrm{h}$ and $\lambda$ are:

$$
\begin{array}{ll}
1.8<\mathrm{h}<31.3 & \mathrm{~W} / \mathrm{m}^{2 \circ} \mathrm{C} \\
1.2 \cdot 10^{-5}<\lambda<7.2 \cdot 10^{-4}, & 1 / \mathrm{s} .
\end{array}
$$

Hence, one sees that the range of heat transfer coefficient, $h$, and cooling coefficient, $\lambda$, for a circular cross-section rod is essentially a function of the rod diameter, material properties, and air velocity and is not strongly dependent upon the ambient air temperature.

As mentioned above, the parameters $\mathrm{h}$ and $\lambda$ are directly proportional to the Nusselt number. The explicit expressions are:

$$
\begin{aligned}
& \mathrm{h}=\mathrm{k}_{\mathrm{f}} \mathrm{Nu} / \mathrm{d} \\
& \lambda=4 \mathrm{k}_{\mathrm{f}} \mathrm{Nu} /\left(\mathrm{d}^{2} \rho \mathrm{c}\right)
\end{aligned}
$$

where $k_{f}$ is the thermal conductivity of air at $T_{f}=T_{\infty}$

$\mathrm{d}$ is the diameter of the circular cross-section rod $\rho c$ is the heat capacity of the rod material. 
Table B-1: Range of Parameters

circular cross-section steel rod with forced convection cooling by air at atmospheric pressure

\begin{tabular}{|l|l|l|l|}
\hline \multicolumn{1}{|c|}{ material } & \multicolumn{1}{c|}{ parameter } & \multicolumn{1}{c|}{ range } & \multicolumn{1}{c|}{ units } \\
\hline air & temperature & $250^{\circ}<\mathrm{T}_{\infty}<400^{\circ}$ & ${ }^{\circ} \mathrm{K}$ \\
\hline air & Prandtl number & $0.689<\mathrm{Pr}<0.722$ & dimensionless \\
\hline air & velocity & $0.1<\mathrm{u}_{\infty}<1.0$ & $\mathrm{~m} / \mathrm{s}$ \\
\hline rod & diameter & $0.05<\mathrm{d}<0.15$ & $\mathrm{~m}$ \\
\hline rod & ratio: perimeter to area & $27<\mathrm{p} / \mathrm{S}<80$ & $1 / \mathrm{m}$ \\
\hline rod & thermal conductivity of steels & $11<\mathrm{k}<60$ & $\mathrm{~W} / \mathrm{m}^{\circ} \mathrm{C}$ \\
\hline rod & heat capacity of steels & $3.5 \cdot 10^{6}<\rho c<4.2 \cdot 10^{6}$ & $\mathrm{~J} / \mathrm{m}^{3 \circ} \mathrm{C}$ \\
\hline rod & thermal diffusivity of steels & $1 \cdot 10^{-6}<\mathrm{\kappa}<2 \cdot 10^{-6}$ & $\mathrm{~m}^{2} / \mathrm{s}$ \\
\hline air-rod & Reynolds number & $190<\mathrm{Re}<13,300$ & dimensionless \\
\hline air-rod & Nusselt number & $8<\mathrm{Nu}<71$ & dimensionless \\
\hline air-rod & heat transfer coefficient & $1.8<\mathrm{h}<31.6$ & $\mathrm{~W} / \mathrm{m}^{2 \circ} \mathrm{C}$ \\
\hline air-rod & cooling coefficient & $1.2 \cdot 10^{-5}<\lambda<7.2 \cdot 10^{-4}$ & $1 / \mathrm{s}$ \\
\hline
\end{tabular}

Appendix B References

B.1 Holman, J.P. Heat Transfer (7th Ed), McGraw-Hill Inc.

B-2 Slocum, A.H.: Precision Machine Design, Prentice Hall (1992) (Table 7.3.1, p.335) 

